\title{
ELASTIC INCOMPATIBILITY STRESSES ACROSS PLANAR AND NONPLANAR GRAIN BOUNDARIES IN SILVER, ALUMINUM, AND ZIRCONIUM APPLIED TO DUCTILE FRACTURE CRITERIA UNDER HIGH TRIAXIAL STRESS
}

\author{
R. Roehnelt, M.E. Kassner, T.C. Kennedy \\ Department of Mechanical Engineering \\ Oregon State University \\ Corvallis, OR 97331 USA \\ and
}

R.S. Rosen

Lawrence Livermore National Laboratory Livermore, CA 94550 USA
RECEIVEO

SEP 201996

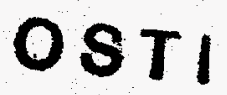

July 2, 1996

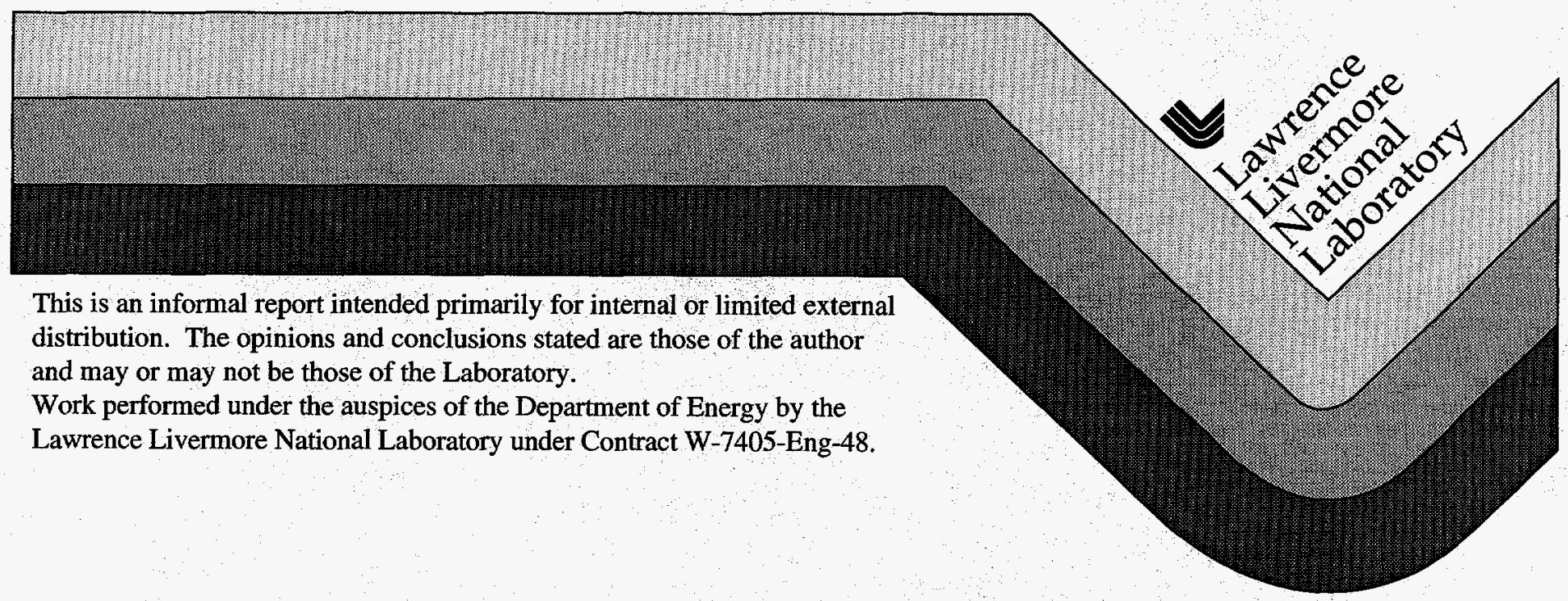

DETRIBUTION OF THIS DOCUMENT IS UNLMITED

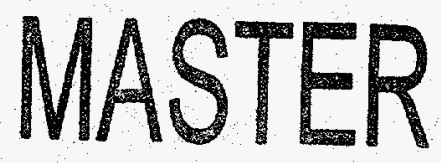




\section{DISCLAIMER}

This report was prepared as an account of work sponsored by an agency of the United States Government. Neither the United States Government nor any agency thereof, nor any of their employees, make any warranty, express or implied, or assumes any legal liability or responsibility for the accuracy, completeness, or usefulness of any information, apparatus, product, or process disclosed, or represents that its use would not infringe privately owned rights. Reference herein to any specific commercial product, process, or service by trade name, trademark, manufacturer, or otherwise does not necessarily constitute or imply its endorsement, recommendation, or favoring by the United States Government or any agency thereof. The views and opinions of authors expressed herein do not necessarily state or reflect those of the United States Government or any agency thereof. 


\section{DISCLAIMER}

Portions of this document may be illegible in electronic image products. Images are produced from the best available original document. 


\title{
Elastic Incompatibility Stresses \\ Across Planar and Nonplanar Grain Boundaries \\ in Silver, Aluminum, and Zirconium \\ Applied to Ductile Fracture Criteria under High Triaxial Stress
}

\author{
R. Roehnelt, M.E. Kassner, T.C. Kennedy \\ Department of Mechanical Engineering \\ Oregon State University \\ Corvallis, OR 97331 USA \\ and \\ R.S. Rosen \\ Lawrence Livermore National Laboratory \\ Livermore, CA 94550 USA
}

\section{INTRODUCTION}

Grain boundaries in a polycrystal imply elastic incompatibilities that can lead to stress states in the vicinity of the interface that are different from the macroscopic or applied stresses because the single crystal elastic properties are not all isotropic. This phenomenon is important as mechanical processes may operate at the microscopic level that would not be predicted based on the macroscopic stress state. This phenomenon has not been widely examined [1-3]. One of the few studies that examined the level of stress-state modification was by Peralta and coworkers $[1,2]$ on copper. More specifically, they determined that slip or plasticity in cyclically deformed copper occurred in areas with high elastic incompatibility stresses.

The focus of the present study is the unstable growth of cavities as a result of high local triaxial stress. Work by Huang, Hutchinson, and Tvergaard (HHT) [4] showed that cavities will expand, unstably, without far-field plasticity for axisymmetric triaxial stress-states in which the 
mean stress, $\sigma_{\mathrm{m}}$, to yield stress, $\sigma_{\mathrm{y}}$, ratio is about 4 and the minor to major principal stress ratio (e.g., $\sigma_{2} / \sigma_{1}$ or $\left.\sigma_{3} / \sigma_{1}\right)$ is greater than about 0.75 . In a recent article by one of the authors of the present work, constrained, thin, silver films were observed to fail by (ductile) microvoid coalescence, without macroscopic plasticity (less than $2 \%$ ) [5]. The constraint placed the silver interlayer into a state of relatively high triaxial stress. The HHT mechanism is attractive in explaining the low macroscopic ductile failure by microvoids. The classic theories for ductile fracture that rely on significant "far-field" plasticity to rationalize cavity growth do not appear applicable here. However, finite element method (FEM) analysis of the macroscopic stress state assuming isotropic elastic properties, suggests that $\sigma_{\mathrm{m}} / \sigma_{\mathrm{y}}$ and $\sigma_{2} / \sigma_{1}$ maybe lower than necessary to activate the unstable plastic growth of cavities. Analogous to the motivation of Peralta et al., we wish to determine the change in magnitude of the mean stress and the ratios of the principal stresses as a result of elastic incompatibilities near planar and non-planar interfaces. Our analysis indicates that, in order for the HHT mechanism to rationalize ductile failure observed in constrained silver thin films, these ratios must change by a factor of about 1.1 to 1.6 , depending on the particular macrostress stress-state. Thus, part of the purpose of this work is to determine whether the elastic incompatibilities associated with both planar and nonplanar interfaces are sufficient to increase $\sigma_{\mathrm{m}} / \sigma_{\mathrm{y}}$ and $\sigma_{2} / \mathrm{q}_{\mathrm{q}}$ to levels sufficient to activate HHT. This work is an important supplement to our earlier work on ductile fracture of metals under high triaxial stress that was published in a companion journal. Naturally, our analysis will provide more general insight into the magnitude (and relevance) of elastic incompatibility stresses in materials. Aluminum was also analyzed to contrast the behavior of silver. 


\section{PROCEDURE}

The first case analyzed was that of planar interfaces between two infinite crystals of silver and zirconium. No previous work of this type was performed on these materials. However, the earlier work of Bassani, Peralta, Llanes, and Laird [1] for copper provided a benchmark to check the validity of our results for any particular FEM code. A finite element analysis using 20-node three-dimensional solid elements was performed for comparison to the FEM analysis performed by Peralta et al. Calculations were performed for a coarse mesh using 400 elements per crystal and for a fine mesh using 2200 elements per crystal, roughly twice the number of the Peralta et al. used in their analysis that used Abaqus. Figure 1 shows the coarse mesh and the orientation of the crystals relative to a global $\mathrm{x}, \mathrm{y}, \mathrm{z}$-coordinate system. The bicrystal results are illustrated in Fig. 2 which shows a plot of the increase in mean stress along a line through the center of the bicrystal, perpendicular to the planar interface. The coarse mesh shows the results of an inadequate mesh density. The slightly greater deviation from the mean stress, near the interface, for the fine mesh is attributed to a larger number of nodes than that of the analysis of Peralta et al. This allows the results to be determined closer to the boundary than would have been otherwise possible. The Abaqus model used by Peralta et al. is apparently reasonable since doubling the number of nodes in the model produces only a small amount of change. The bicrystal results illustrated in Fig. 2 are for a central path perpendicular to the interface, excepting the analytic Peralta et al. data which refers to an infinite bicrystal "near" the interface. The low values shown by the Peralta et al. analytical work are due to the assumption that changes in the stress across the interface were equal in magnitude but of opposite sign, which is a necessary 
assumption for simplifying the analysis but sacrifices a great deal of accuracy as compared to FEM analysis.

Once a model for the planar interface had been established to be reasonable, the single crystal elastic constants were changed from those of copper to silver with identical structure and similar anisotropy ratios ( 3.27 and 3.21 , respectively). [The anisotropy ratio is defined by $2 \mathrm{C}_{44} /\left(\mathrm{C}_{11}-\mathrm{C}_{12}\right)$ where 1.0 defines isotropic materials.]

The local coordinate systems of the two crystals were initially set parallel to the global coordinate system (Fig. 1). The bicrystal was then loaded with one of the cryatals rotated following the scheme of $[\mathrm{G}][\mathrm{A}][\mathrm{B}]$ where $[\mathrm{G}]$ is the rotation matrix around local $\mathrm{z},[\mathrm{A}]$ is the rotation matrix about local $\mathrm{x}$, and $[\mathrm{B}]$ is the rotation matrix about local $\mathrm{y}$. These correspond to the [001], [100], and [010] directions for silver and aluminum and [0001], [2110], and [0110] directions for zirconium (hcp). The principal stresses were calculated along a line running through the central region of the bicrystal parallel to the global $z$ axis. These principal stresses were then used to determine the mean stress and the minor to major principal stress ratios.

There is no known benchmark for nonplanar (serrated or wedge) interface analysis. The mesh density adequacy was checked by analyzing results for the case of no misorientation across the boundary. Additionally, the data from node to node was examined to check for discontinuities in both value and slope for non-zero misorientations.

\section{RESULTS}

Finite element analyses of stress incompatibilities were performed on silver, zirconium, and aluminum. Each will be discussed separately. 


\section{Silver}

\section{Planar Interfaces}

Two stress states were examined for planar interfaces, one in which the ratios of the principal stresses are $0.5,0.5,1.0$ (Fig. 3), and another with the ratios of $0.68,0.68,1.0$ (Fig. 4). These axisymmetric stress states were chosen since they reflect cases where the minor to major principal stress state ratios are 0.5 and 0.68 , relatively high, but less than the 0.75 value necessary to activate the HHT mechanism. The objective is to determine whether, for a variety of crystallographic misorientations, the changes in $\left(\sigma_{\mathrm{m}} / \sigma_{\mathrm{y}}\right)$ and $\left(\sigma_{2} / \sigma_{1}\right.$ and $\left.\sigma_{3} / \sigma_{1}\right)$ are sufficient to activate HHT unstable cavity growth. These stress ratios examined are also those for which low macrostrain ductile microvoid coalescence failures were observed in our earlier work published in a companion journal.

Figures $3 a$ and $b$ and $4 a$ and $b$ illustrate the effects of elastic incompatibilities for a variety of rotations of one crystal with respect to the other. First, for the $(0.5,0.5,1.0)$ stress state, and a "typical" misorientation of $30-35^{\circ}$, it appears that the mean stress increases by a factor of about 1.1 ; the maximum is about 1.13. The increase in the ratio of the average of the minor (minimum) stresses to the maximum (major) stress is a factor of 1.2 to a ratio of about 0.60 .

For the $(0.68,0.68,1.0)$ stress state, the mean stress increases by a factor of about 1.04 (1.07 maximum), and the ratios of the minor to major principal stress increase by a factor of, typically, about 1.07 or to a ratio of about 0.73 . In this case, it appears that the elastic incompatibility may increase the ratio of the (average) minor principal stress to major principal stress ratio to at least very near the necessary level to activate HHT. However, the mean stress to yield stress ratio of about 2.2 observed for fracture in silver [5] would not increase sufficiently 
to activate unstable cavity growth. In the first stress-state, the increase in the minor to major principal stress ratio is modest, at 0.60 and HHT appears less likely. (This latter case represents delayed failures where the rate sensitivity of $\sigma_{\mathrm{y}}$ must be considered. It is possible that $\sigma_{\mathrm{m}} / \sigma_{\mathrm{y}}$ may be sufficient for unstable cavity growth with this consideration although the principal stress ratios appear too small to activate HHT ductile failure.)

\section{Serrated Interfaces}

Our transmission and scanning electron microscopy revealed that the grain boundaries are nonplanar in the constrained thin silver films [5]. Instead, they are clearly serrated. For this reason, we determined the additional effect of nonplanar interfaces on the elastic incompatibility stresses across a grain boundary. Figure 5 illustrates the basic element, or wedge, of what may be the case for the most nonplanar interface, the serrated boundary. Three stress states were investigated for silver with a serrated boundary, principal stress ratios of $(0,0,1.0),(0.5,0.5$, $1.0)$, and $(0.68,0.68,1.0)$. The important finding is that there is an additional "amplification" of the mean stress as well as the ratios of the typical minor to major principal stresses. These are illustrated in Figs. 6, 7, and 8.

First, for uniaxial tension $(0,0,1.0)$, the mean stress near the tip of a serration in silver increases by a factor of, typically, 2.4 , which is relatively large. The typical ratio of the minor to major principal stress is 0.23 with a maximum of about 0.28 . Thus, for uniaxial tension, elastic incompatibility in nonplanar interfaces results in a significant increase in the state of triaxiality, although an insufficient increase to activate the HHT unstable cavity growth. Next, 
in Fig. 7 , for the $(0.5,0.5,1.0)$ stress state, the mean stress increases by a factor of, typically, 1.25 to a maximum of nearly 1.45 (as compared with the typical 1.1 for planar interfaces in Fig. 2) and the minor to major principal stress increases by a factor of only about 1.08 (to a 0.54 ratio), somewhat lower than 0.60 for planar interfaces. For the $(0.68,0.68,1.0)$ stress state in

Fig. 8, the mean stress increases by a factor of about 1.14 and the minor to major principal stresses do not appear to change substantially and increase to only 0.69 . These last two cases do suggest that there is clearly an increase in triaxiality. It does not appear, by itself, however, sufficient to activate the HHT mechanism. Other sources of stress amplification (e.g., dislocation pile-ups) may be required to activate this mechanism. As mentioned earlier, the maximum stress amplification appears to be largest at the tips of the serrated interfaces. This is illustrated in Fig. 9 which shows the distribution of the mean stress along a path passing through the tip of the serrated interface.

\section{Aluminum}

Analysis analogous to that of silver was performed on aluminum, which has a lower anisotropic factor than silver (1.1 vs. 3.21$)$. The principal stress ratio examined was $(0.5,0.5$, 1.0) which represents the magnitude of stress frequently observed in aluminum interconnects [6]. These interconnects are known to cavitate under these high triaxial stresses, and we were interested in determining whether these typical stresses could be "amplified" to activate unstable cavity growth by the HHT mechanism. 


\section{$\underline{\text { Planar }}$}

For planar interfaces, the mean stress increases by only a factor of about $1.02(10 \mathrm{a})$. The ratios of the principal stresses $(10 \mathrm{~b})$ are similar. The von Mises stress may decrease by a factor of about $1.04(10 \mathrm{a})$.

\section{Serrated}

The results of Fig. 10(c) indicate, however, that the mean stress does not increase substantially (only 1.03-1.05). The ratio of the minor to major principal stress (10d) are nearly unchanged. The von Mises stress increases (10c) by a factor of 1.04 .

\section{Zirconium}

Similar analyses to the above were performed on zirconium at $623 \mathrm{~K}$. The plots are shown in Figs. 11 and 12.

\section{Planar}

For the case of a $(0.5,0,1.0)$ stress state (the case of a pressure vessel [7]) in a zirconium bicrystal in Fig. 11, the mean stress is only expected to increase by a factor of less than 1.06 or so. The minor to major principal stress changes by less than a factor of about 1.03 . For a $(0.5$ 0.51 .0 ) stress state (for comparison purposes with aluminum and sliver), the mean stress appears to increase by only a factor of 1.03-1.05 (11a), and the principal stress ratios by about a factor of 1.06-1.12 (Fig. 12b). 


\section{Serrated}

For uniaxial tension across a serrated interface (Fig. 13), the mean stress may decrease by roughly $10 \%$ while the principal stress ratios are about unchanged. For the pressure vessel case $(0.5,0,1.0)(13 a)$, the mean stress is relatively unchanged. The von Mises or effective stress appears to decrease by $2 \%$ or so. The ratios of the principal stresses (14b) are about unchanged. These cases were for the base of the serrations. For a position $40 \%$ "down" from the tops of the serrations (towards the base), the mean stress (14a) may actually decrease by approximately $4 \%$. The von Mises stress may decrease slightly, typically about 5\%. The ratios of the principal stresses may increase by approximately $2 \%$. These results may not be surprising in view of the relatively small anisotropy factor of zirconium. In this case ductile fracture by HHT unstable cavity growth without far-field plasticity cannot be solely facilitated by elastic incompatibilities. Similar results are shown in Fig. 12 for $(0.5,0.5,1.0)$.

\section{CONCLUSIONS}

1. Increases in the hydrostatic component of the stress state is established near bicrystal boundaries due to elastic incompatibilities. The magnitude of the increase are related to the level of elastic anisotropy of the material.

2. Additional elastic incompatibility stress can be provided by nonplanar interfaces.

3. The incompatibility stress increases, measured both by increases in the mean or hydrostatic stresse and the ratio of the smallest to largest principal stresses, do not appear sufficient to rationalize the unstable growth of cavities without far-field plasticity and associated with low 
macroscopic-strain ductile, microvoid-coalescence failures for macroscopic stress-states that are significantly (30-50\%) lower than the unstable cavity growth criterion.

\section{ACKNOWLEDGMENTS}

The financial support from the National Science Foundation under CMS-9522206 is greatly appreciated. Two of the authors (RSR and RR) were partly supported by Lawrence Livermore National Laboratory under contract W-7405-Eng-48 from the U.S. Department of Energy and one of the authors (RR) was also supported under subcontract B324164 to Oregon State University.

\section{REFERENCES}

1. P. Peralta, L. Llanes, J. Bassani, and C. Laird, Phil. Mag., 70A, 1994, pp. 219-232.

2. P. Peralta, A. Schober, and C. Laird, Mater. Sci. and Eng., A169, 1993, pp. 43-51.

3. J. Gemperlova, V. Paidar, and F. Kroupa, Czech. J. Phys., B39, 1989, pp. 1427-1446.

4. Y. Huang, J.W. Hutchinson, and V. Tvergaard, J. Phys. Mech. Solids, 39, 1991, pp. 223241.

5. M.C. Tolle and M.E. Kassner, Acta Metall. et Mater., 43, 1995, pp. 287-297.

6. M. Kato, H. Niwa, H. Yagi, and H. Tsuchikawa, J. App. Phys., 68, 1990, pp. 334-338. 


\section{LIST OF FIGURES}

Figure 1. Finite element mesh for the bicrystal interface.

Figure 2. Comparison of the alterations in the mean stress across the interface of a copper bicrystal using analytical and various numerical techniques. (Copper anisotropy ratio $=3.27)$

Figure 3. The changes in the mean stress (a) and principal stress ratios (b) with various misorientations across a planar silver bicrystal interface with $(0.5,0.5,1.0)$ principal stress ratios. (Silver anistropy ratio $=3.21$ )

Figure 4. The changes in the mean stress (a) and principal stress ratios (b) with various misorientations across a planar silver bicrystal interface with $(0.68,0.68,1.0)$ principal stress ratios.

Figure 5. "Wedge element" Serrated (non-planar) boundary.

Figure 6. The changes in the mean stress (a) and principal stress ratios (b) with various misorientations across a serrated silver bicrystal interface with $(0,0,1.0)$ principal stress ratios.

Figure 7. The changes in the mean stress (a) and principal stress ratios (b) with various misorientations across a serrated silver bicrystal interface with $(0.5,0.5,1.0)$ principal stress ratios.

Figure 8. The changes in the mean stress (a) and principal stress ratios (b) with various misorientations across a serrated silver bicrystal interface with $(0.68,0.68,1.0)$ principal stress ratios. 
Figure 9. The variation of the mean and von Mises stress across the bicrystal for various depths below the "peak" of a serrated silver interface.

Figure 10. The changes in the mean stress (a) and principal stress ratios (b) with various misorientations across a planar aluminum bicrystal interface with $(0.5,0.5,1.0)$ principal stress ratios. The changes in the mean stress (c) and principal stress ratios (d) with various misorientations across a serrated aluminum bicrystal interface with $(0.5,0.5,1.0)$ principal stress ratios (Aluminum anistropy ratio $=1.1)$.

Figure 11. The changes in the mean stress (a) and principal stress ratios (b) with various misorientations across a planar zirconium bicrystal interface with $(0.5,0.5,1.0)$ principal stress ratios. (Zirconium anistropy ratio $=1.2$ )

Figure 12. The changes in the mean stress (a) and principal stress ratios (b) with various misorientations across a planar $623 \mathrm{~K}$, zirconium bicrystal interface with $(0.5,0.5$, 1.0) principal stress ratios.

Figure 13. The changes in the mean stress (a) and principal stress ratios (b) with various misorientations across a serrated $623 \mathrm{~K}$, zirconium bicrystal interface with $(0,0,1.0)$ principal stress ratios.

Figure 14. The changes in the mean stress (a) and principal stress ratios (b) with various misorientations across a serrated $623 \mathrm{~K}$, zirconium bicrystal interface with $(0,0.5$, 1.0) principal stress ratios. 


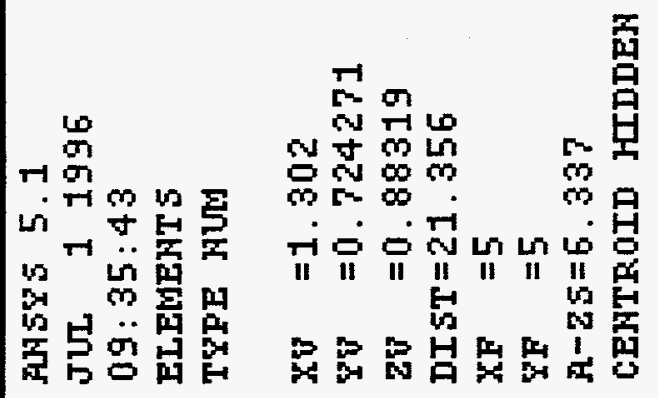

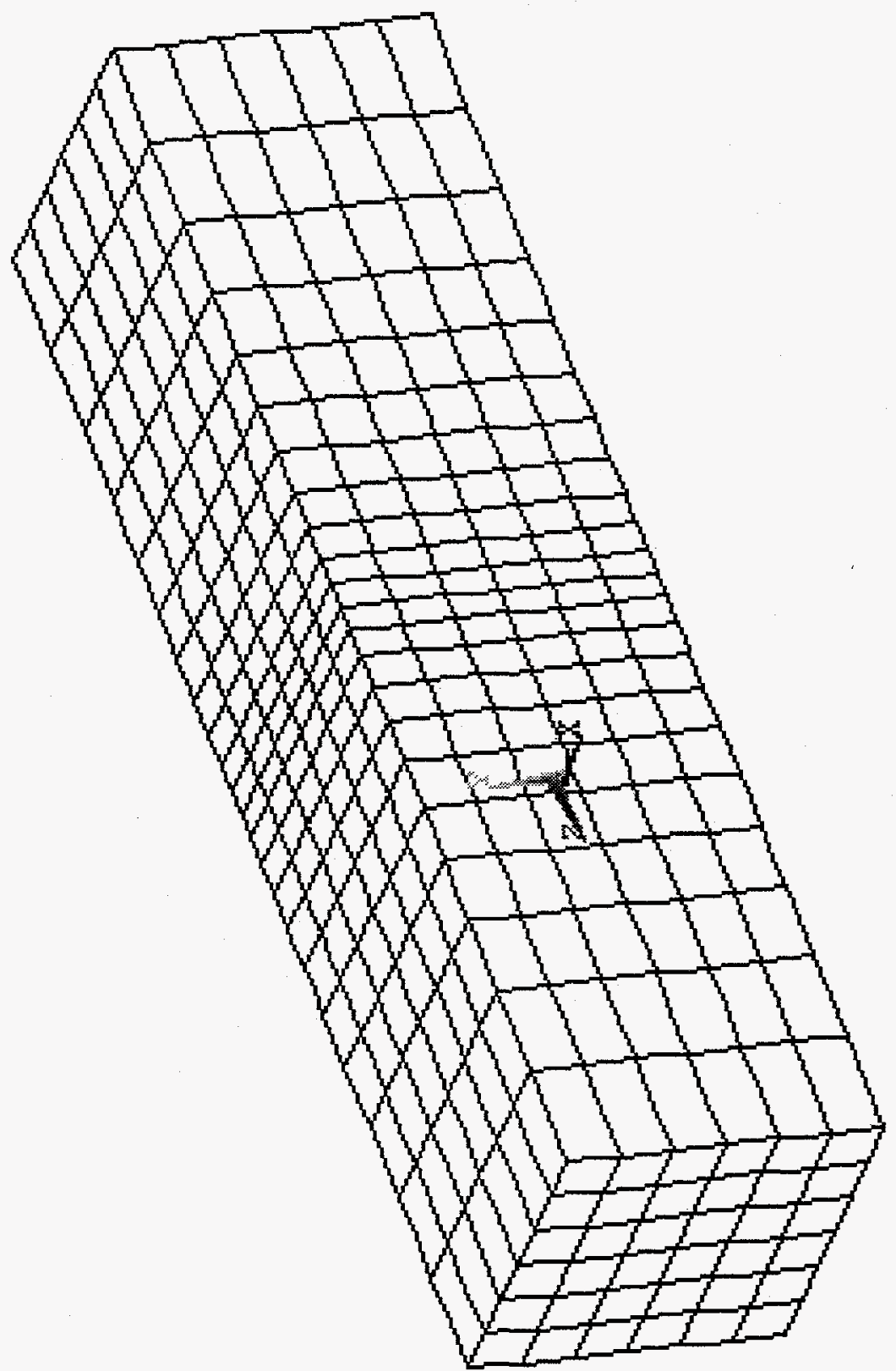




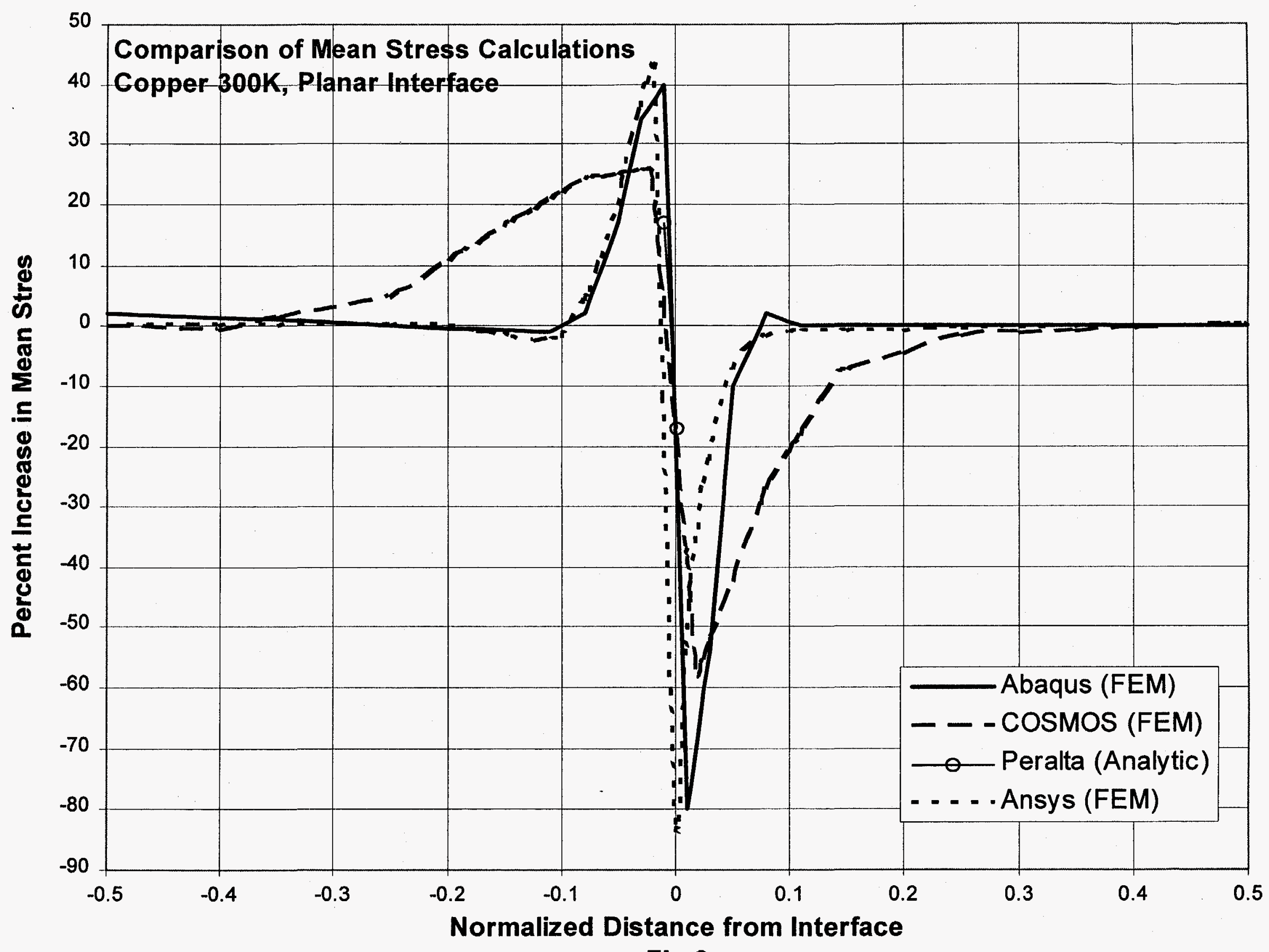

Fig 2 


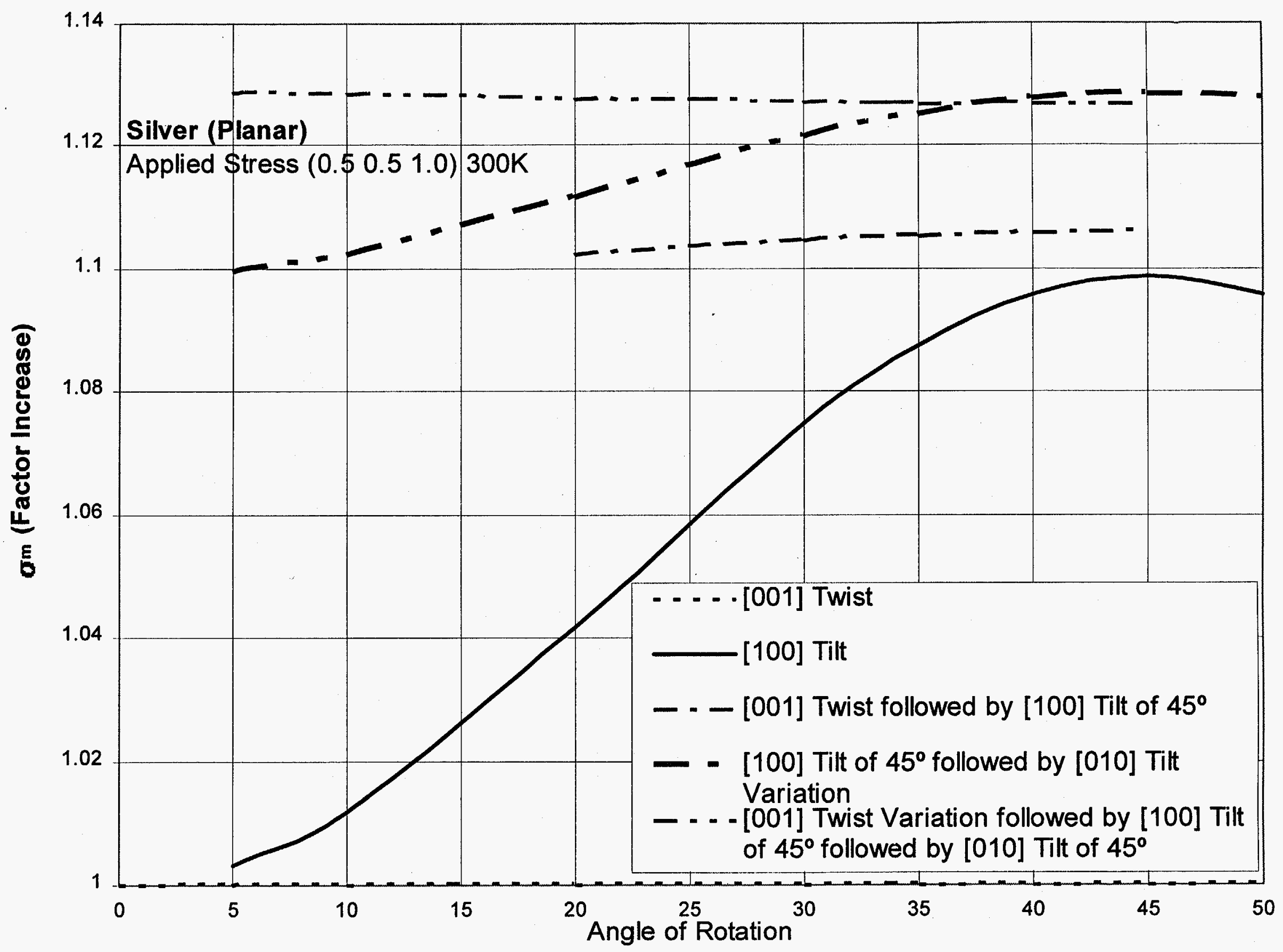

Fig 3a 


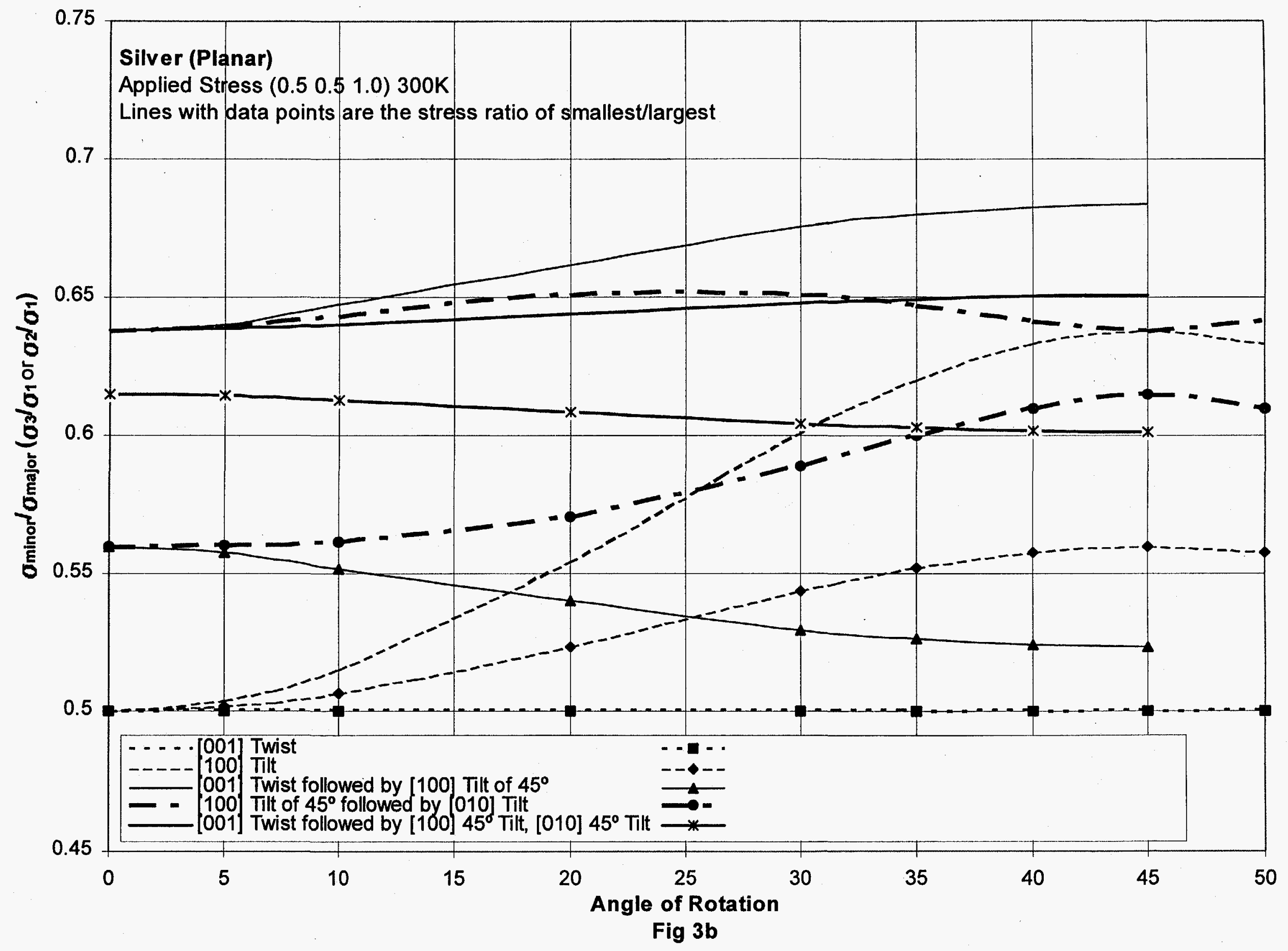




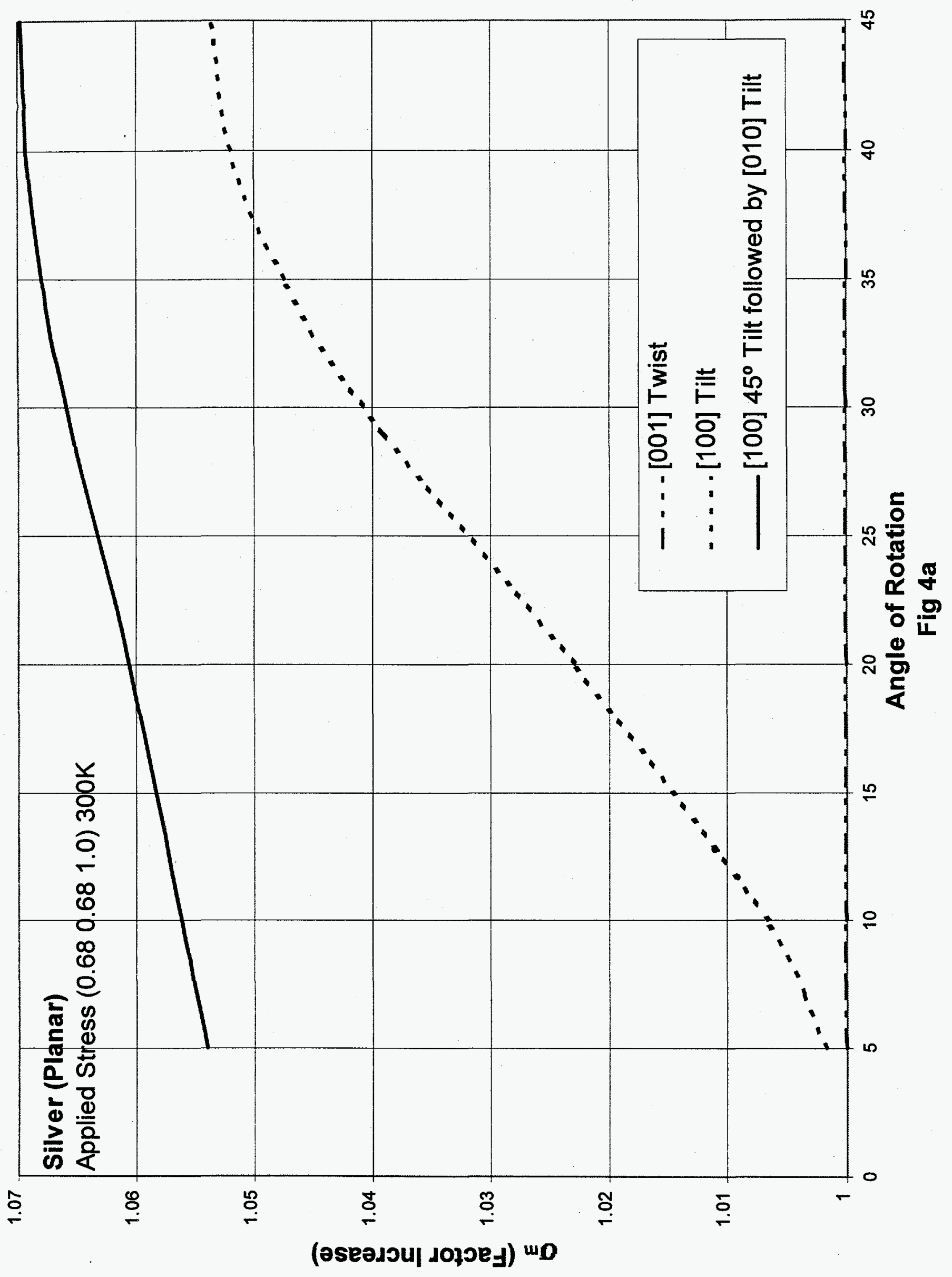




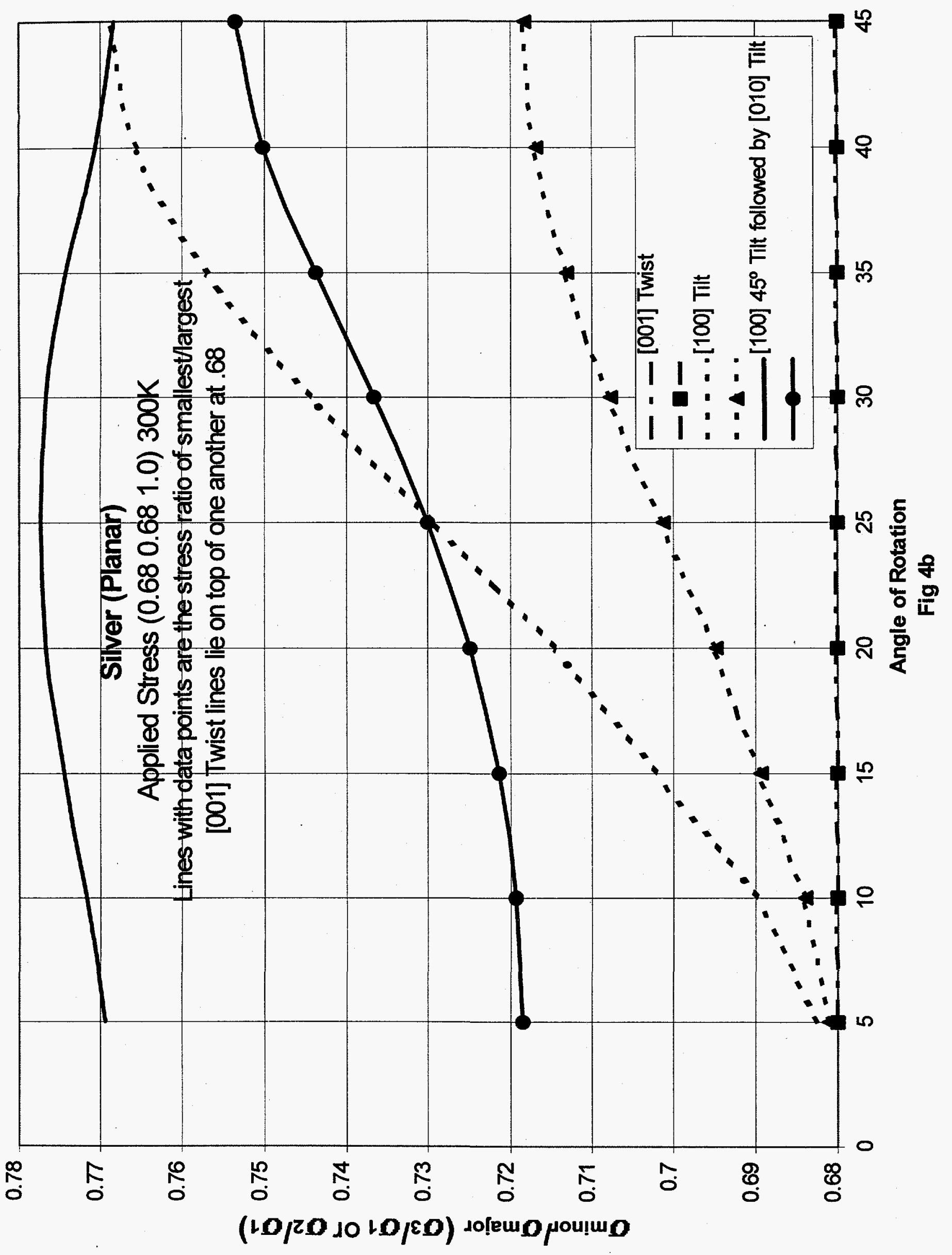




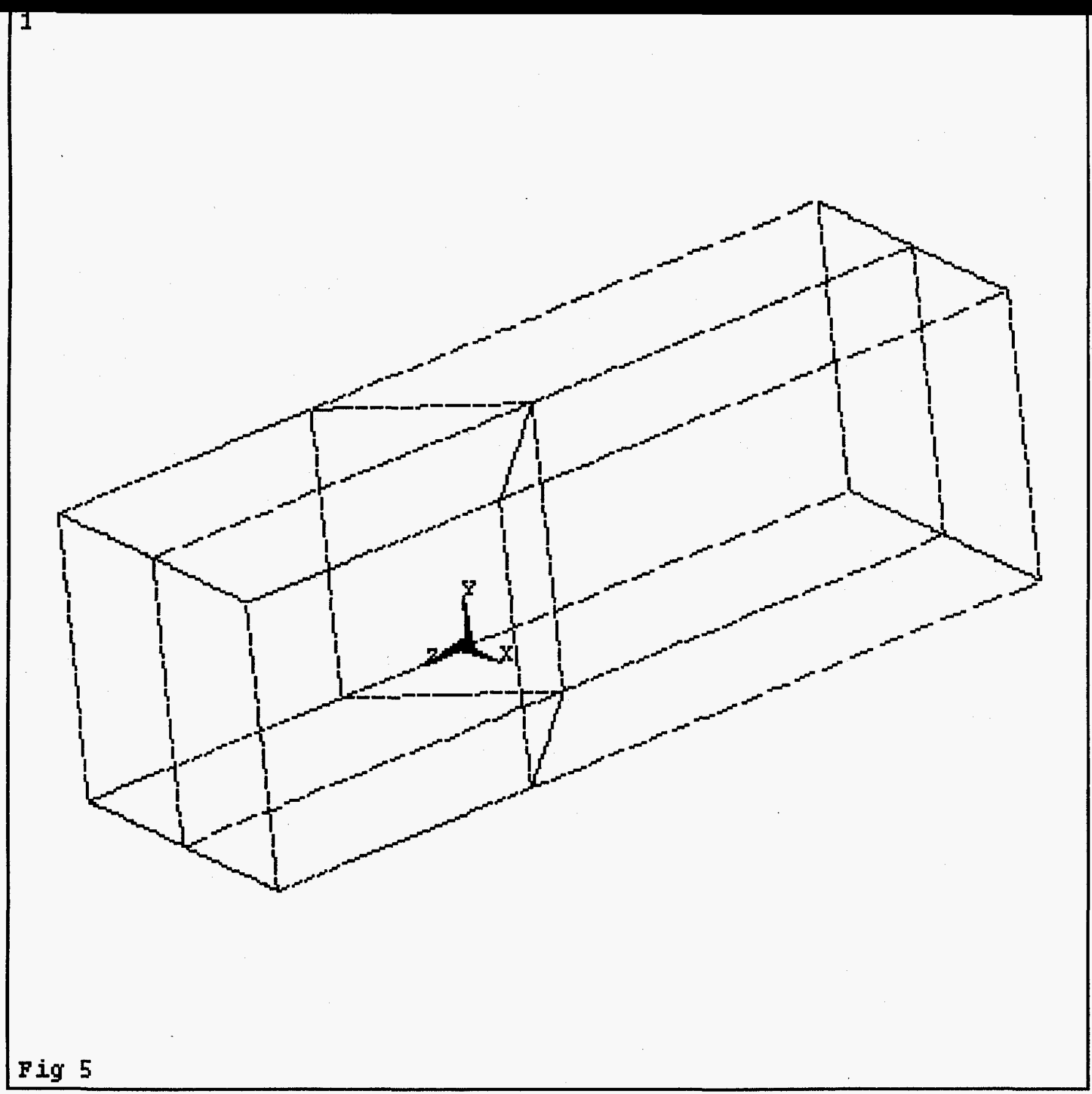

HHSTS 5.1

Jus $10 \quad 1996$

$10: 11: 16$

LIHE S

ESTS HUN

$x y=1.302$

Yv $=0.724271$

$20=0.88319$

DIST $=16.974$

$X F=5$

$Y F=5$

$A-Z 5=6.337$

CEHTROID HUIDEH 


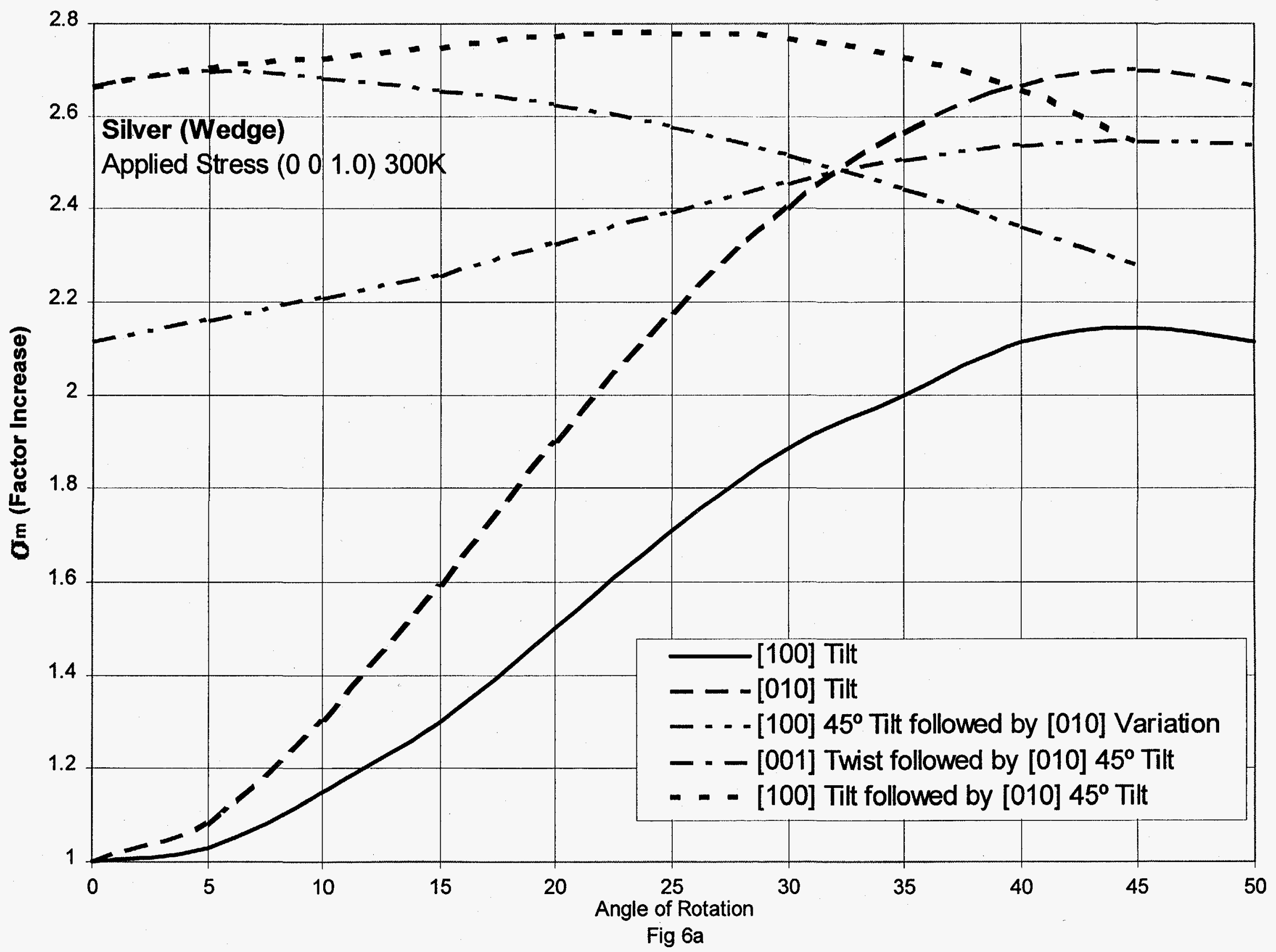




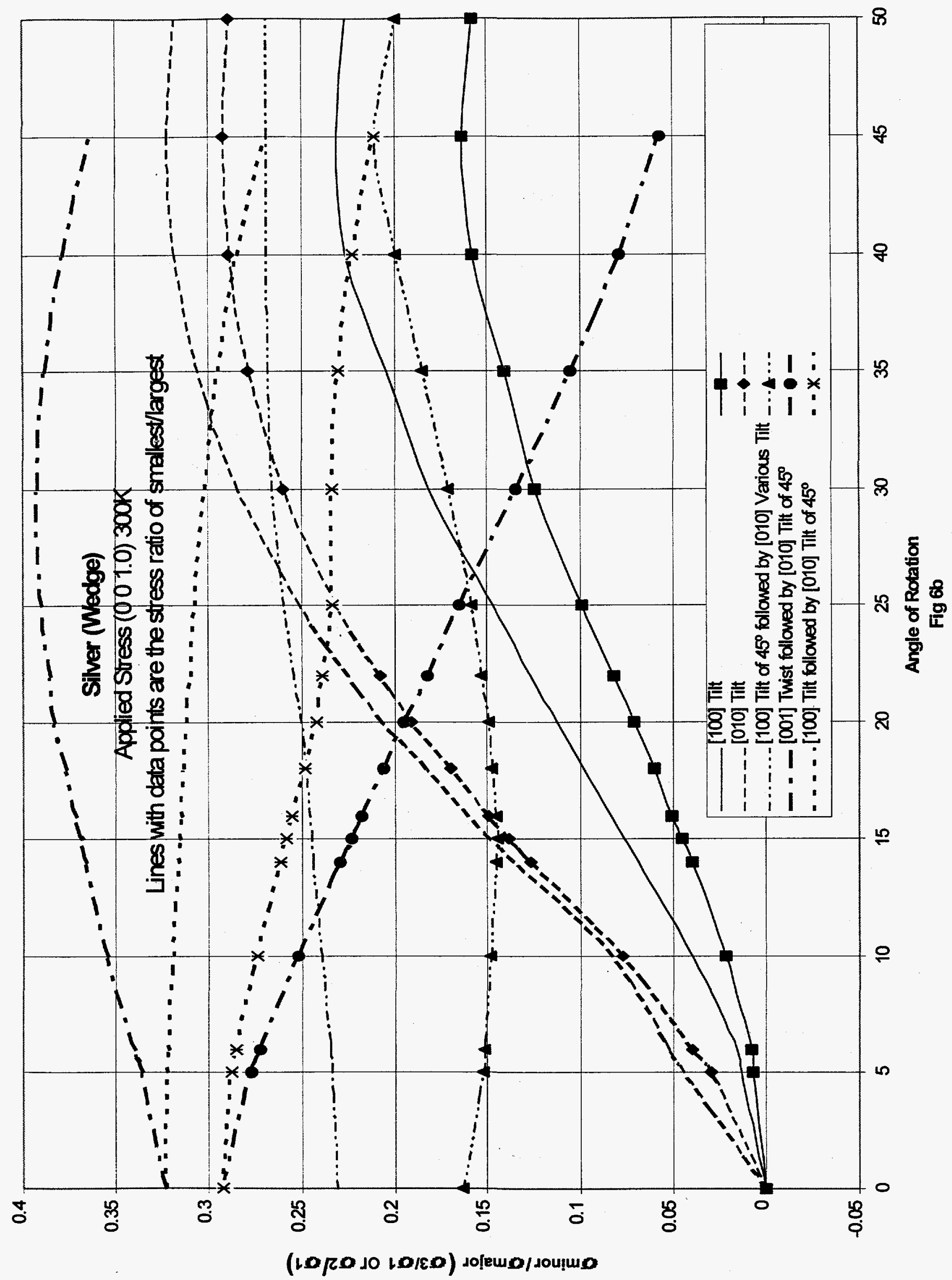




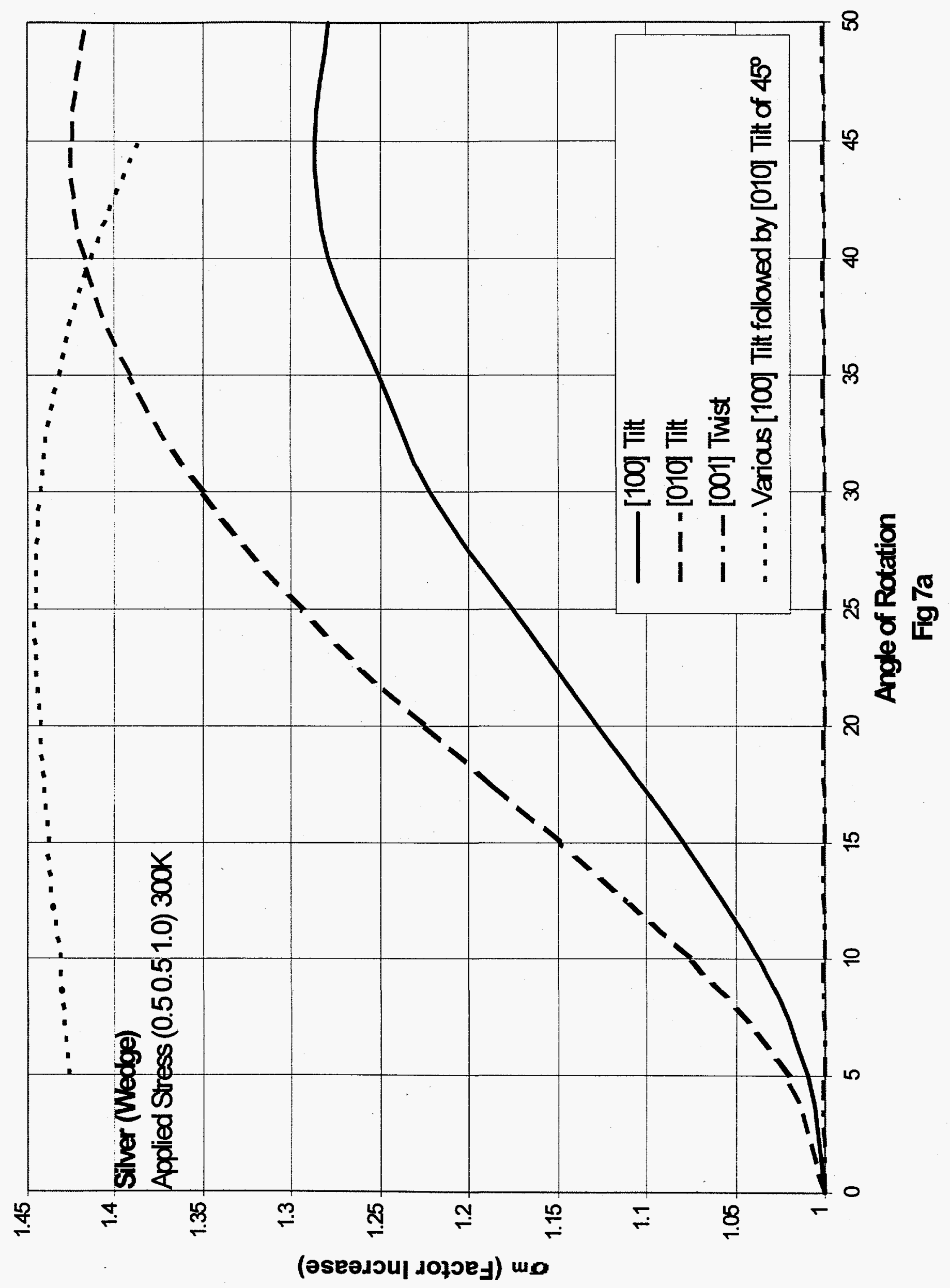




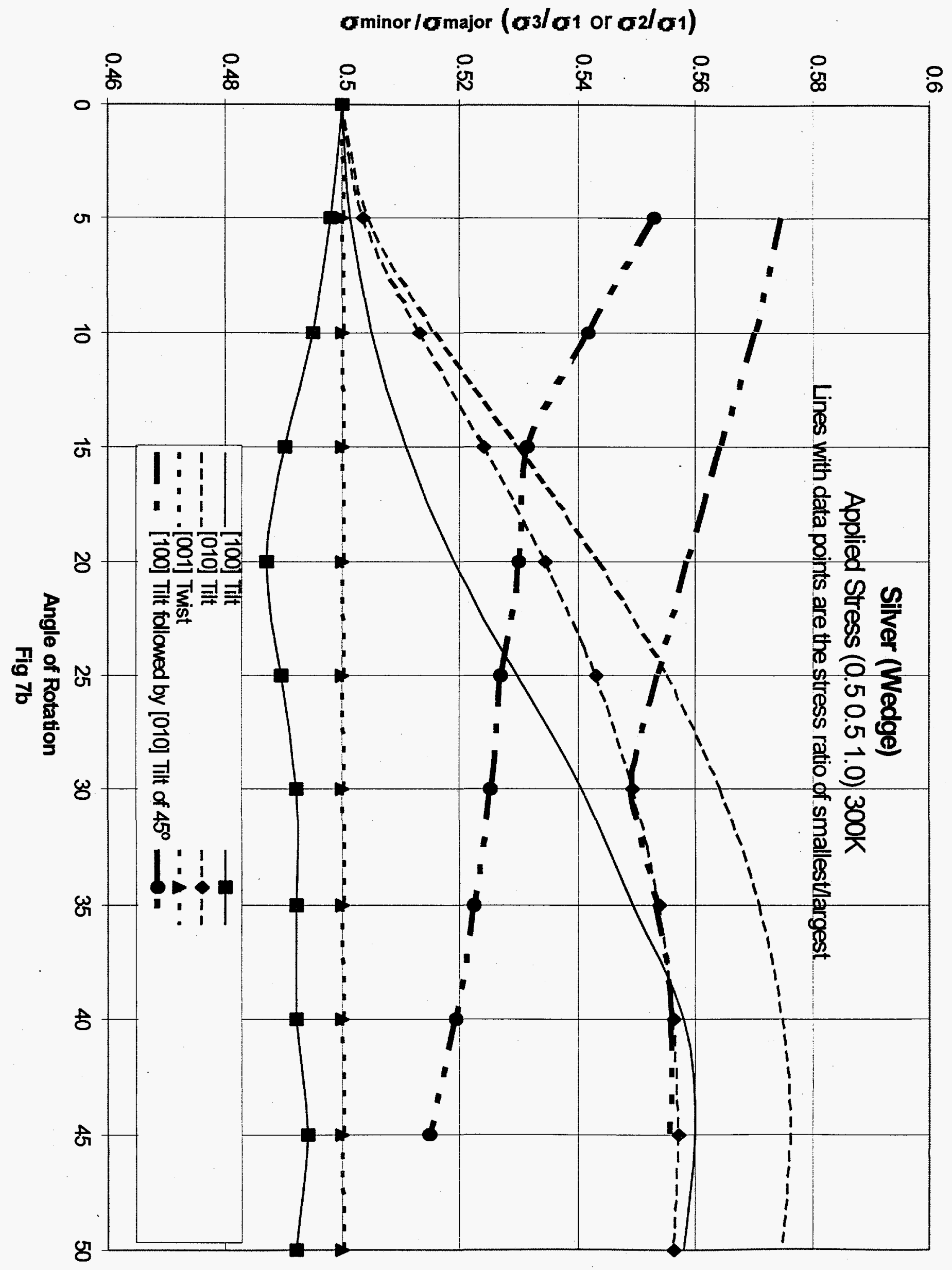




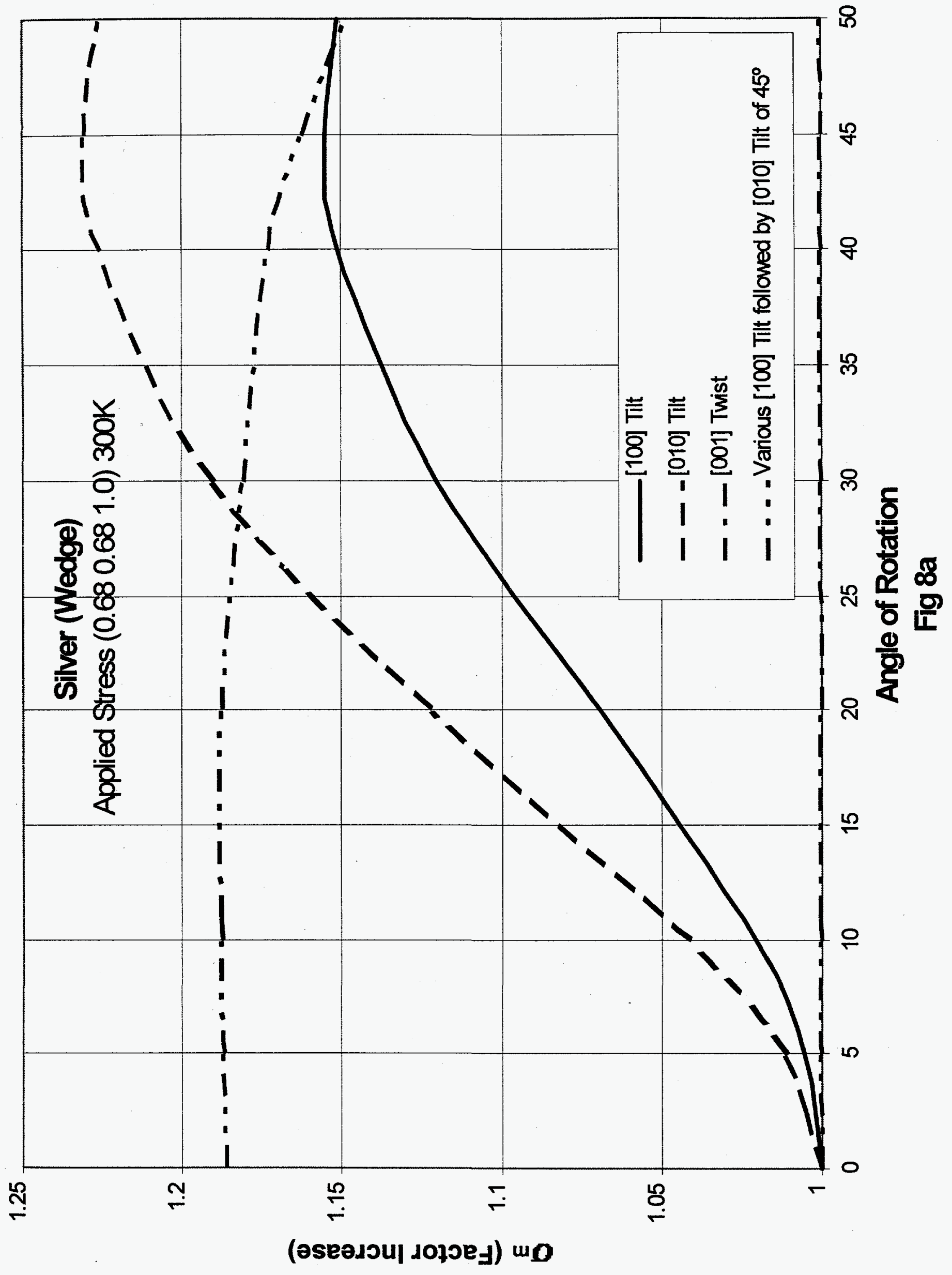




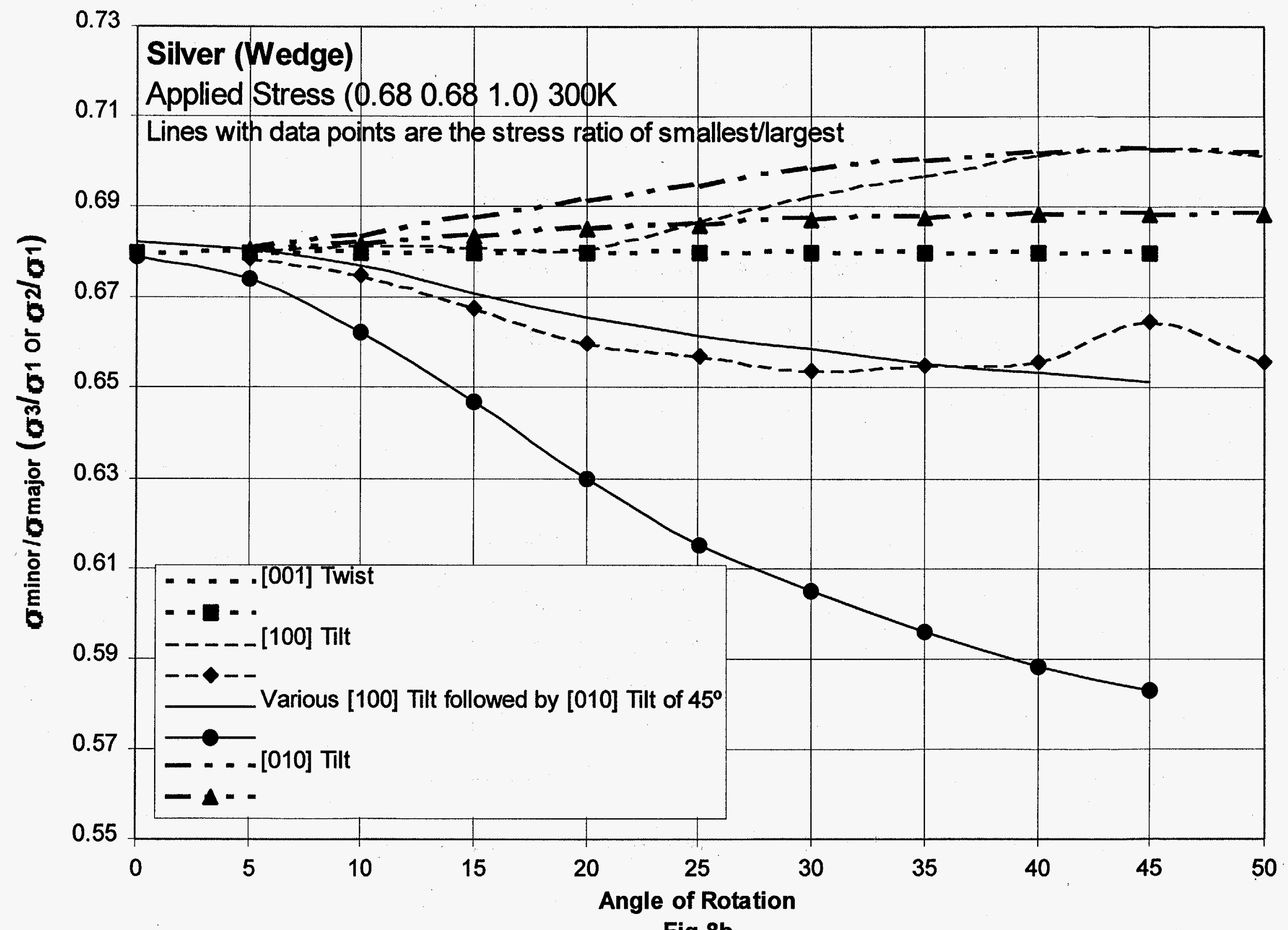

Fig $\mathbf{8 b}$ 


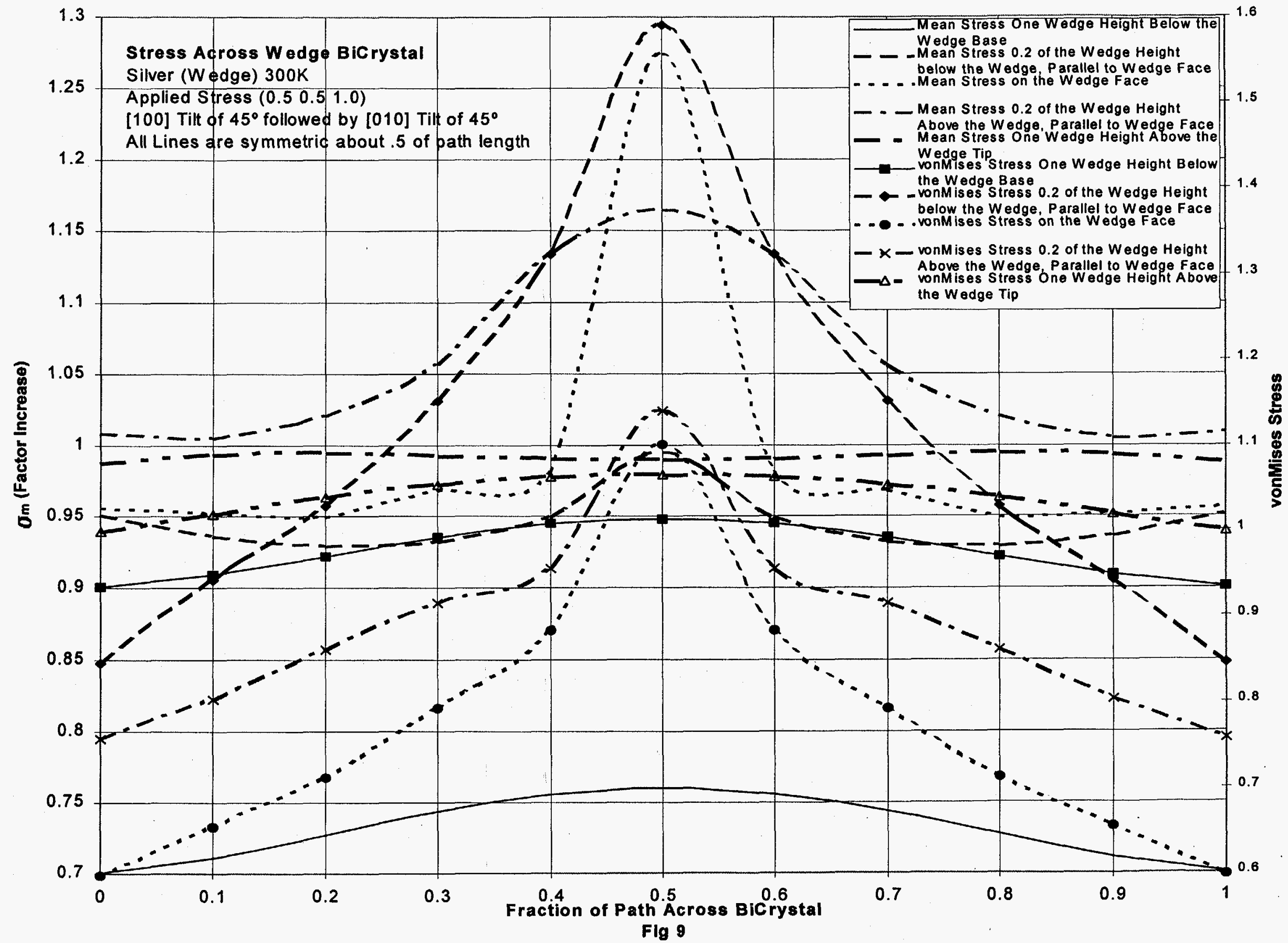




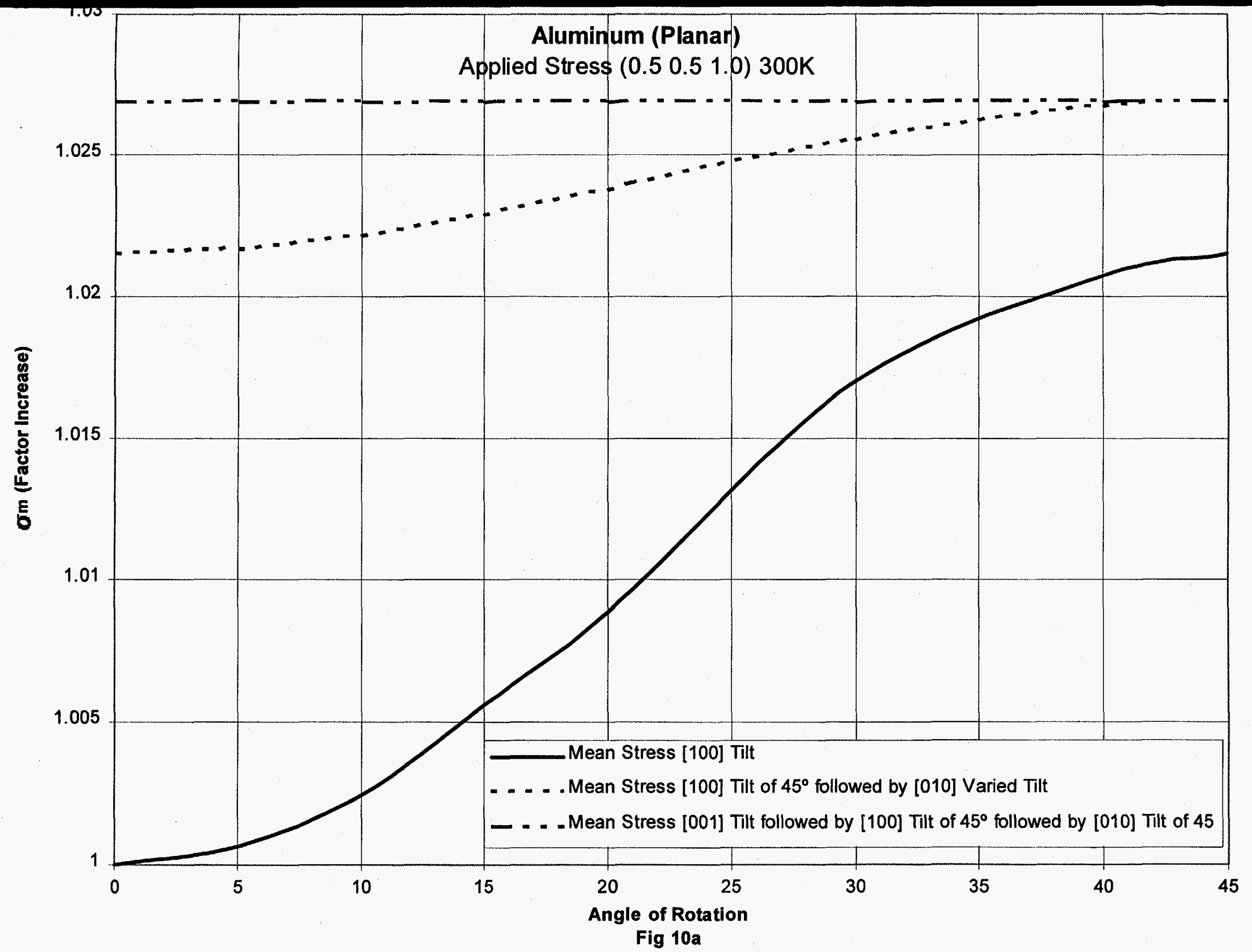




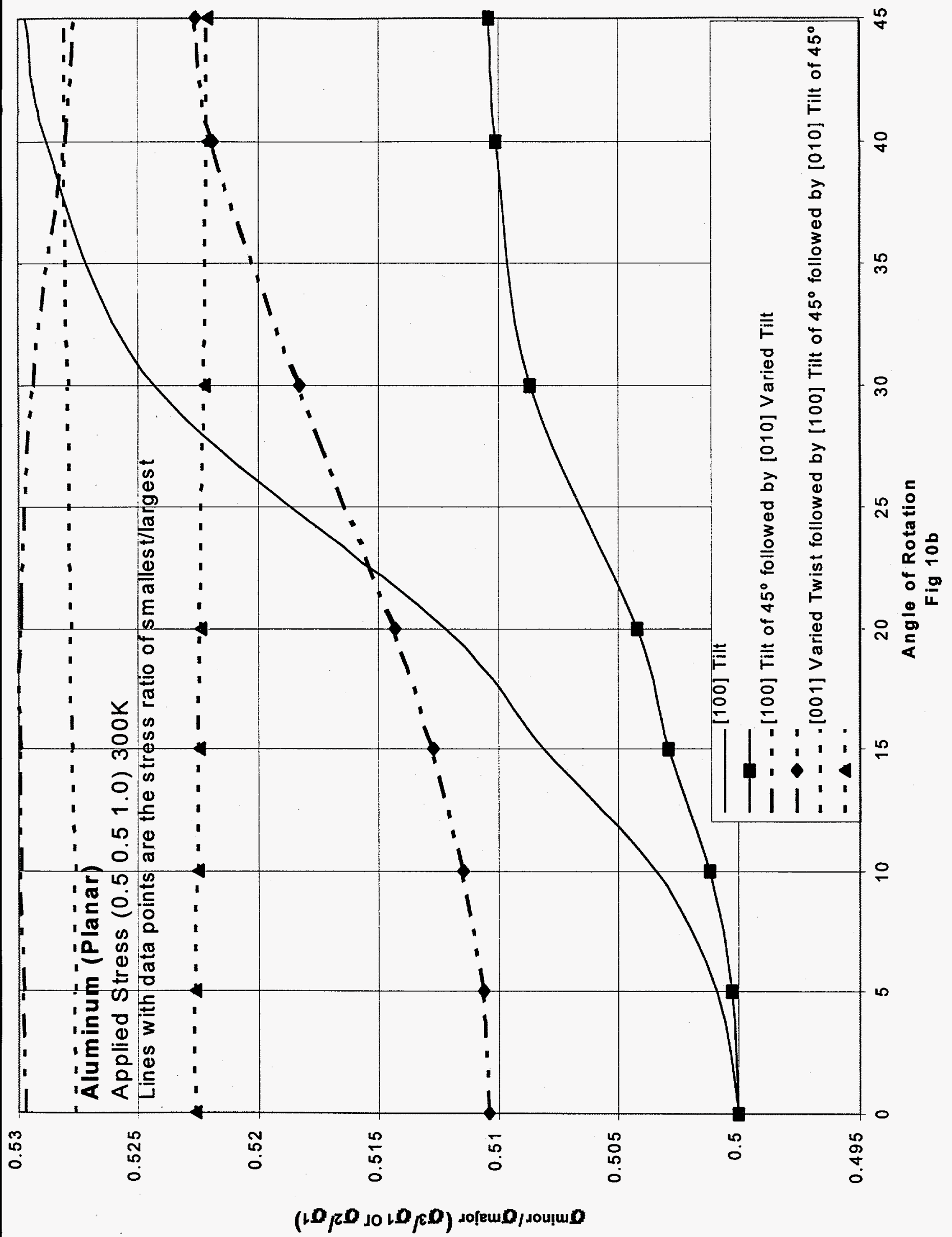




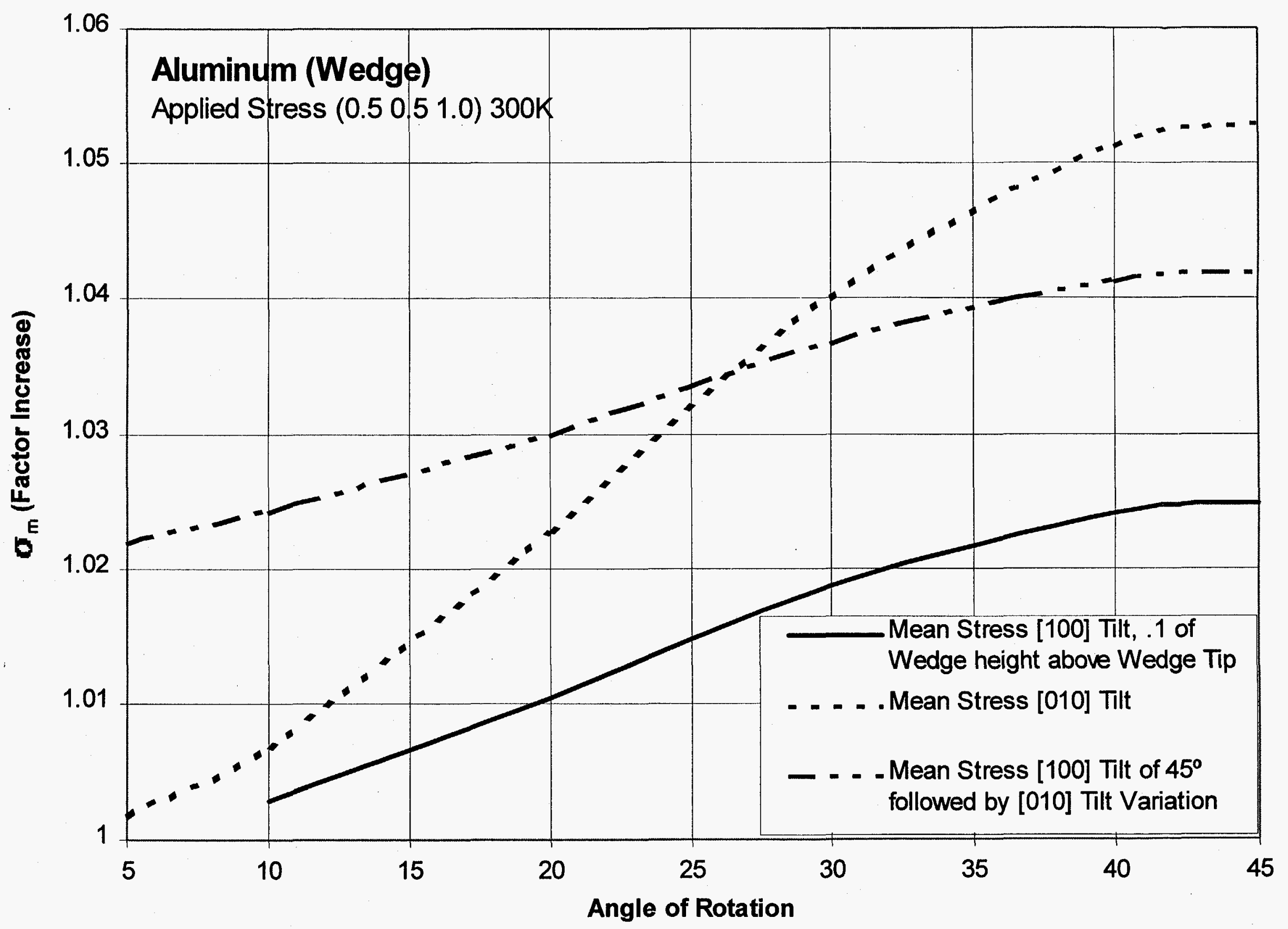

Fig 10c 


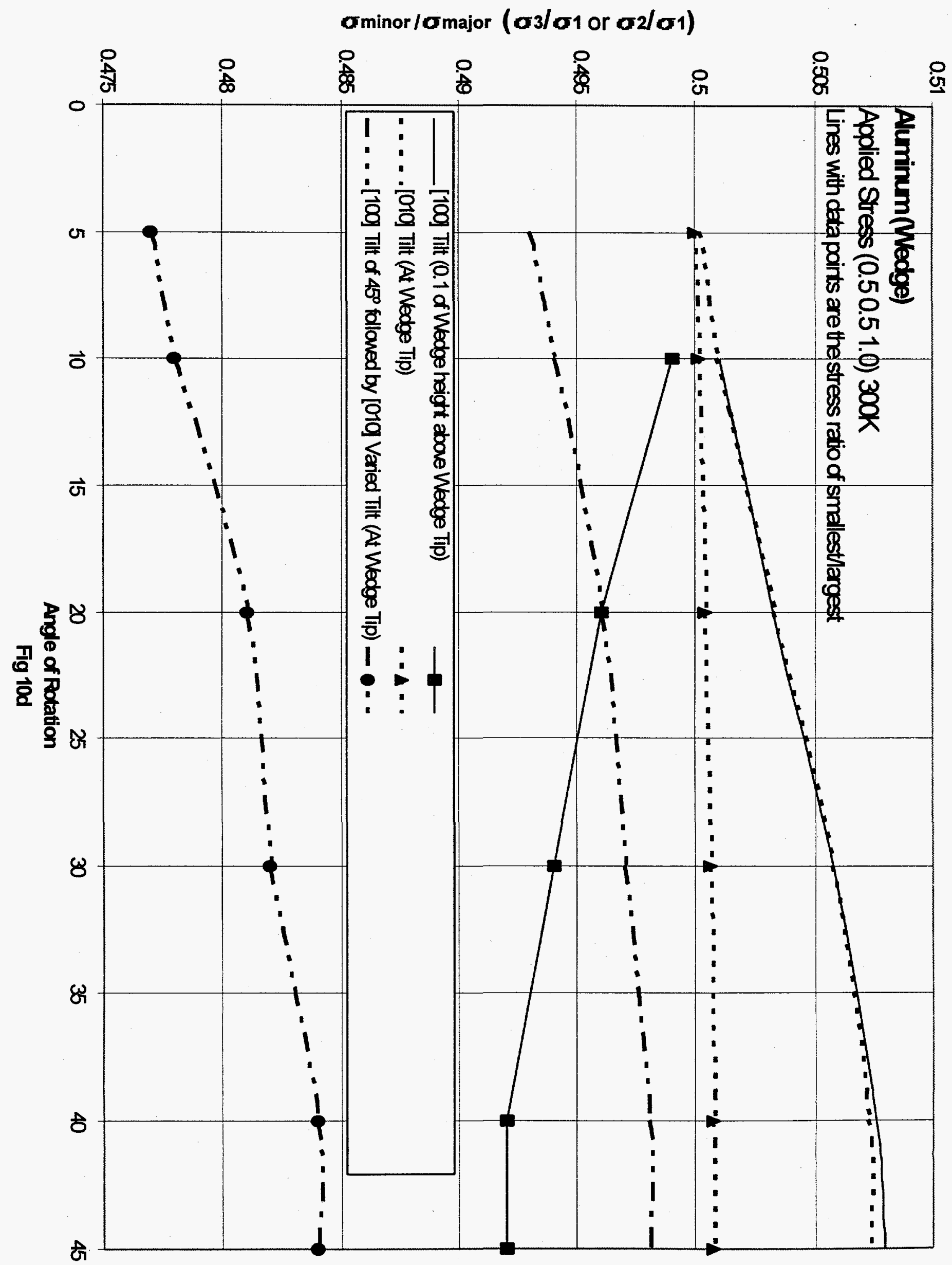




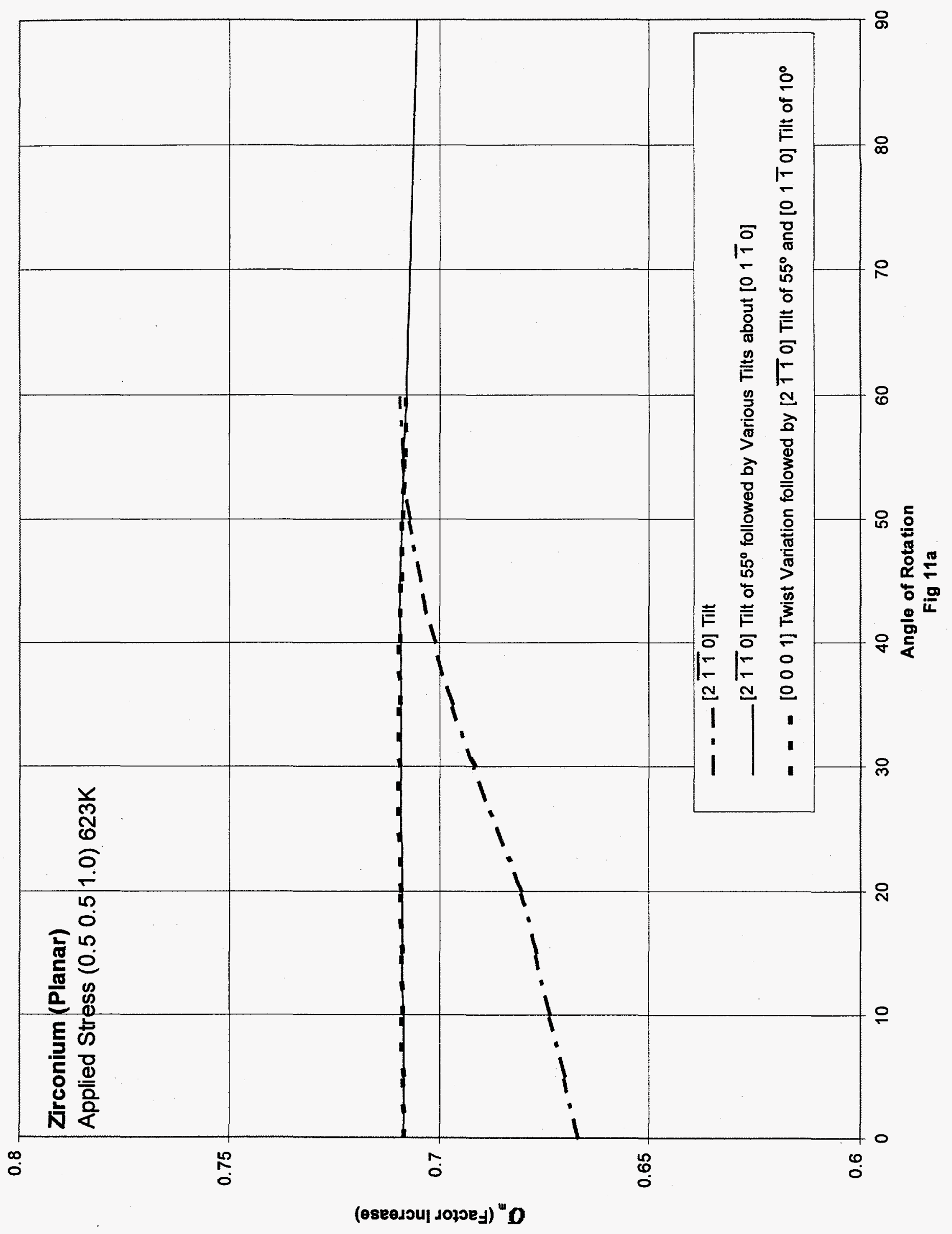




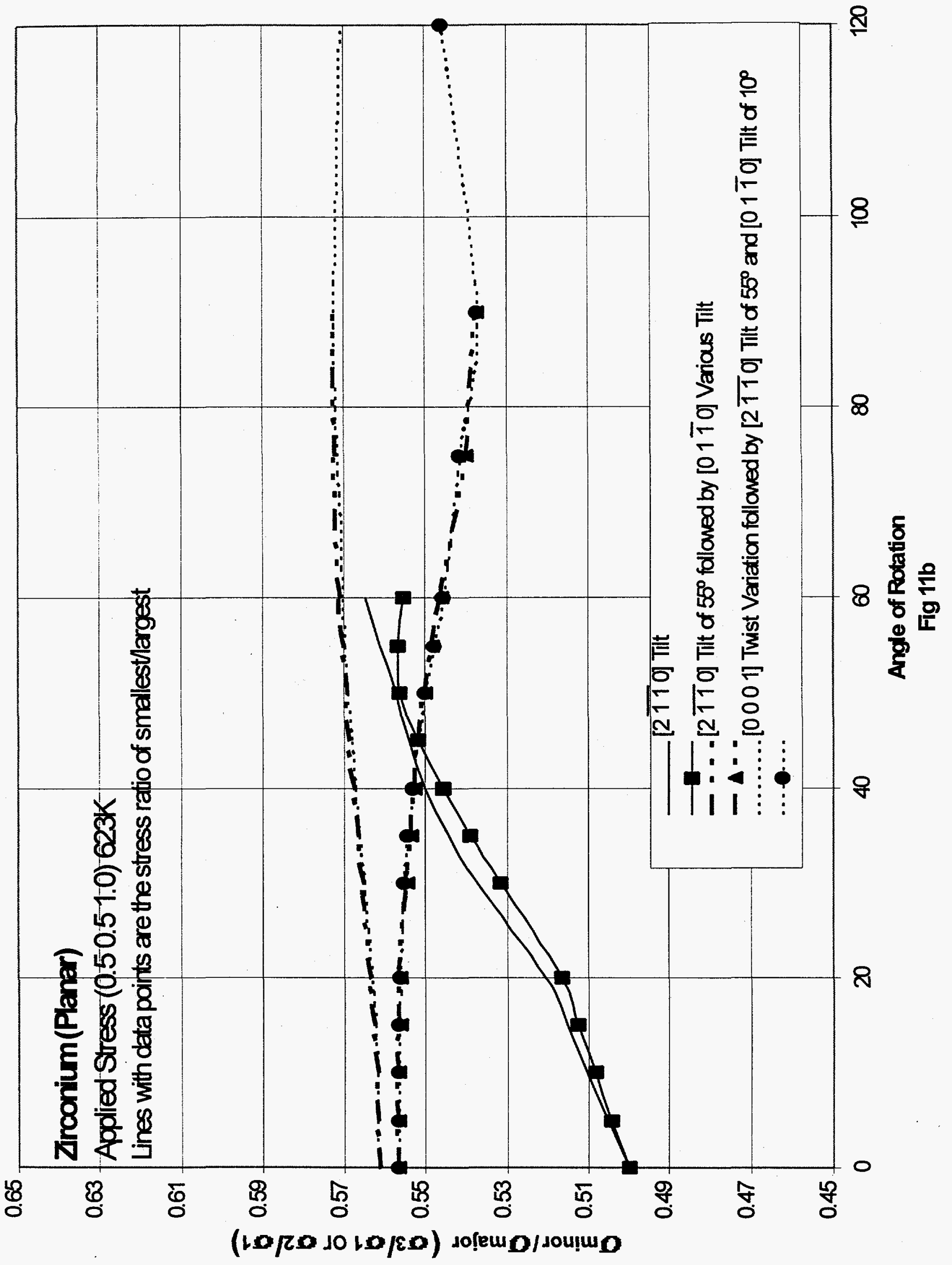




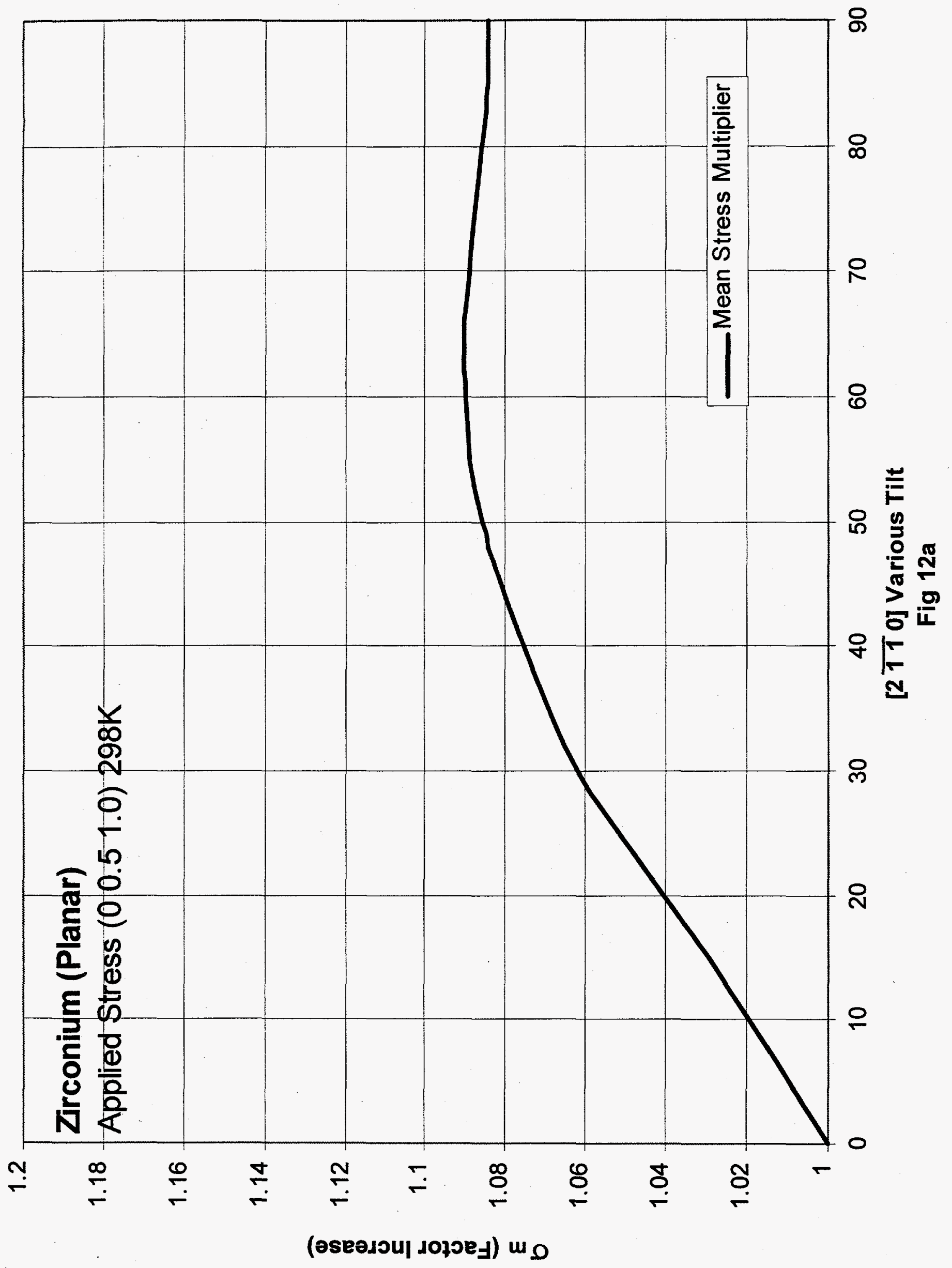




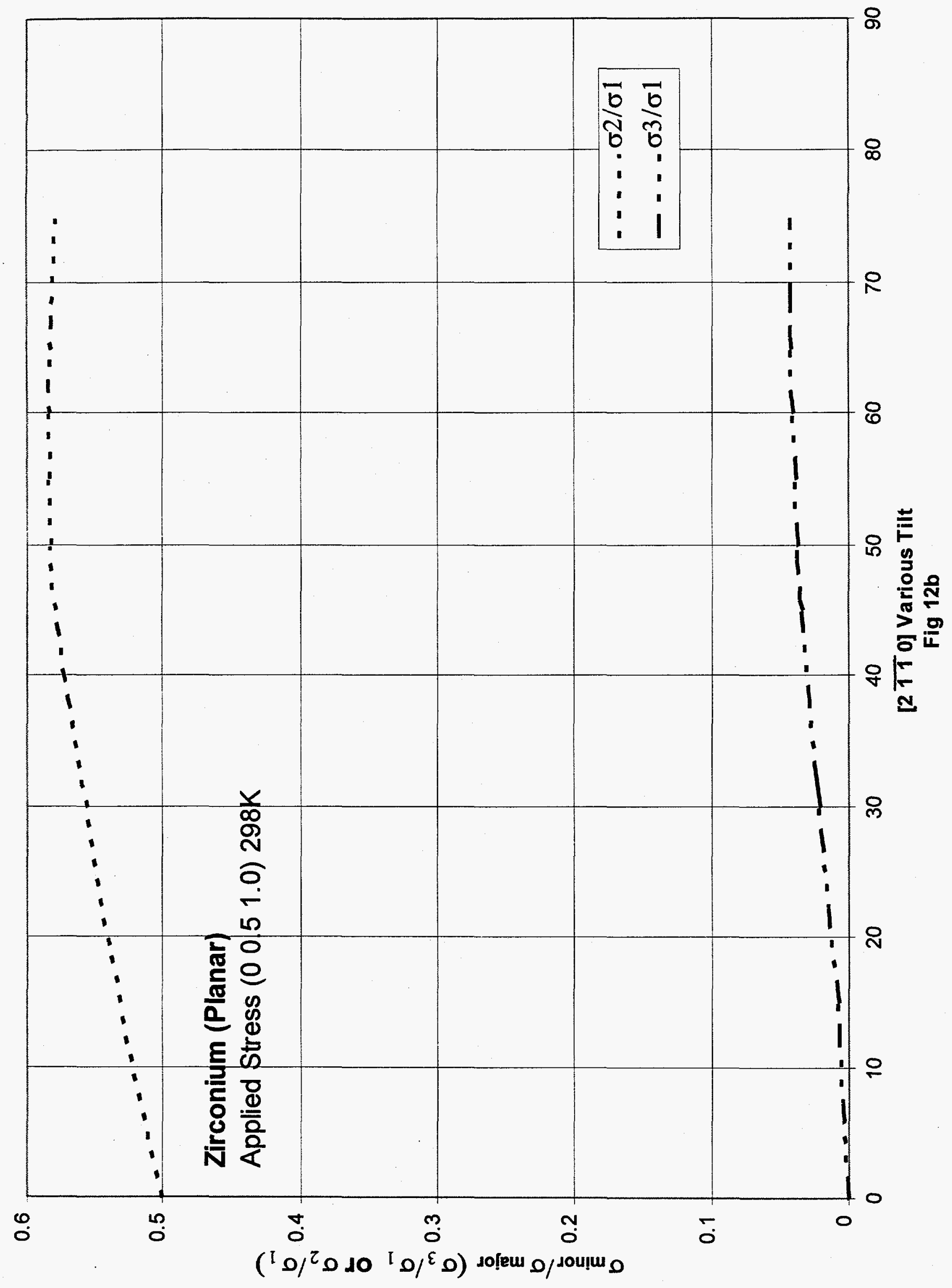




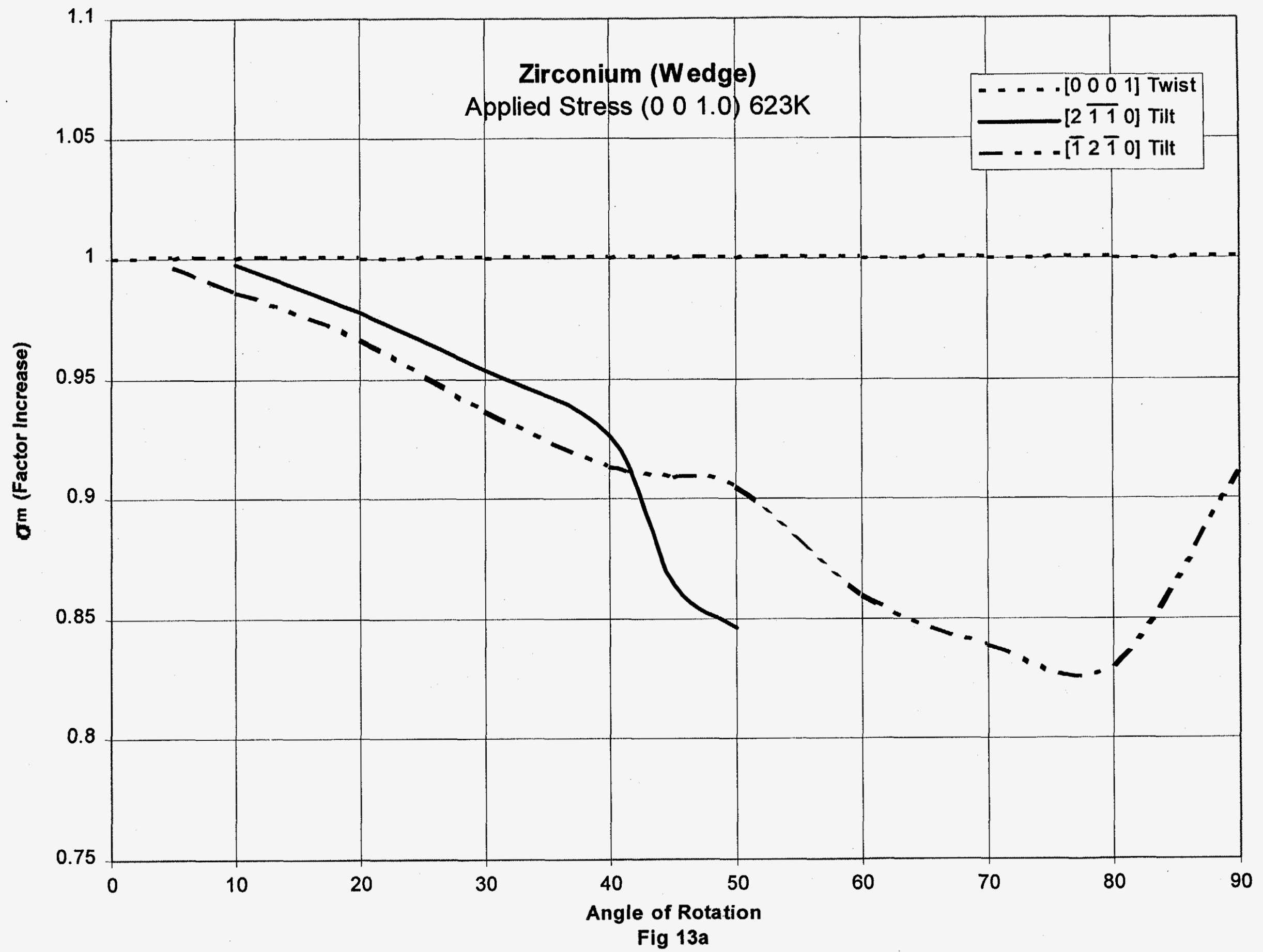




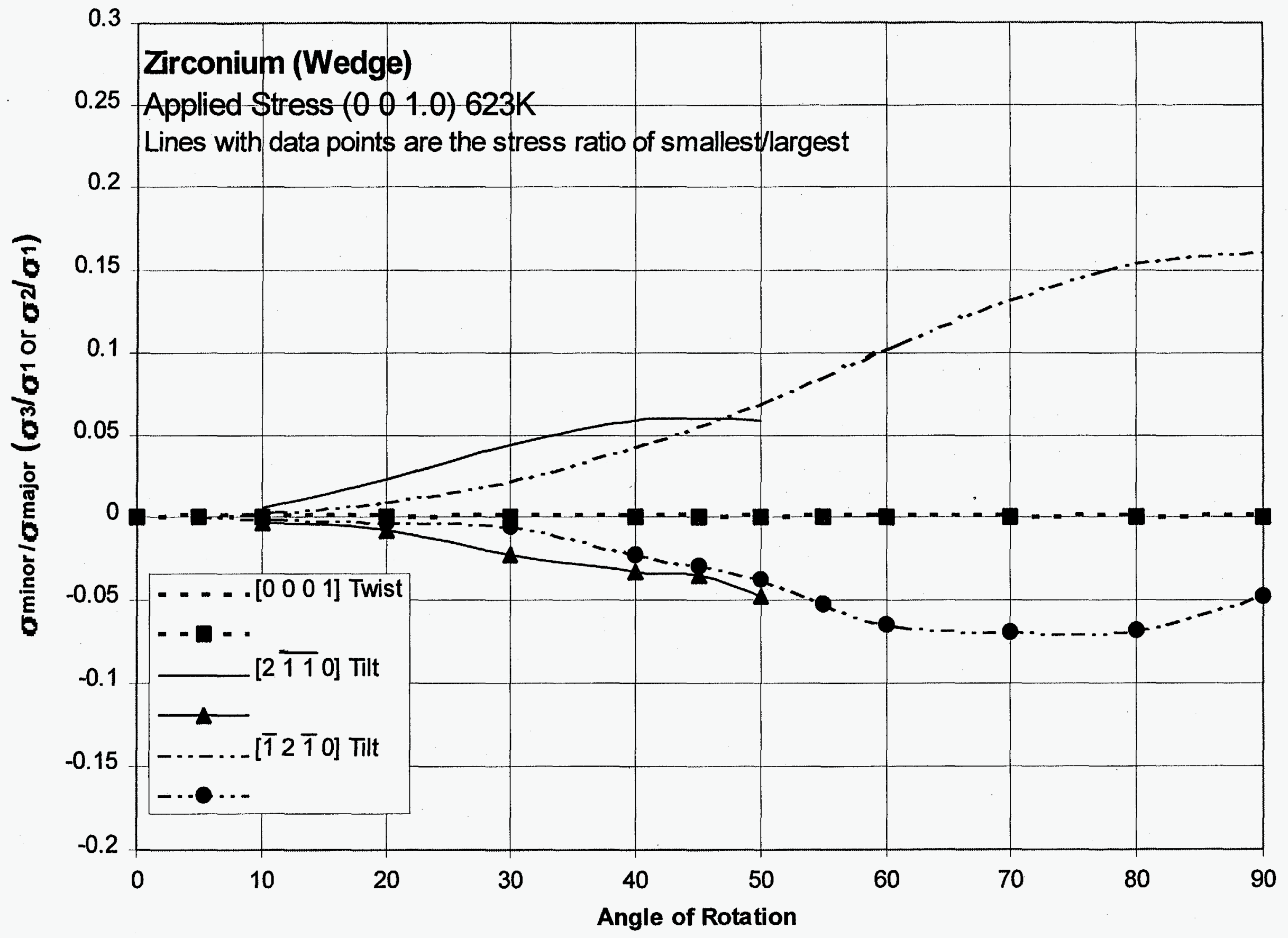

Fig 13b 


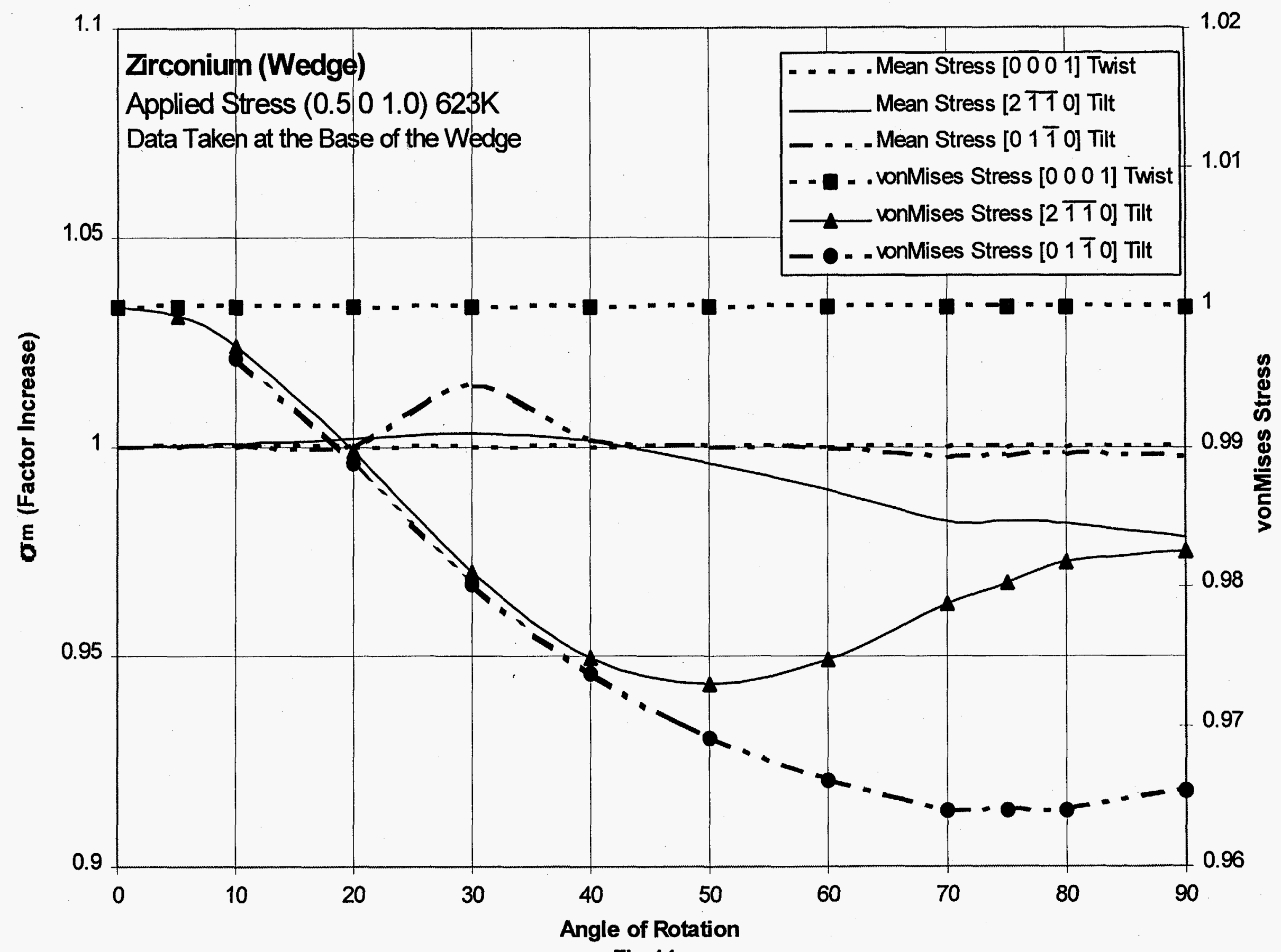

Fig $14 a$ 


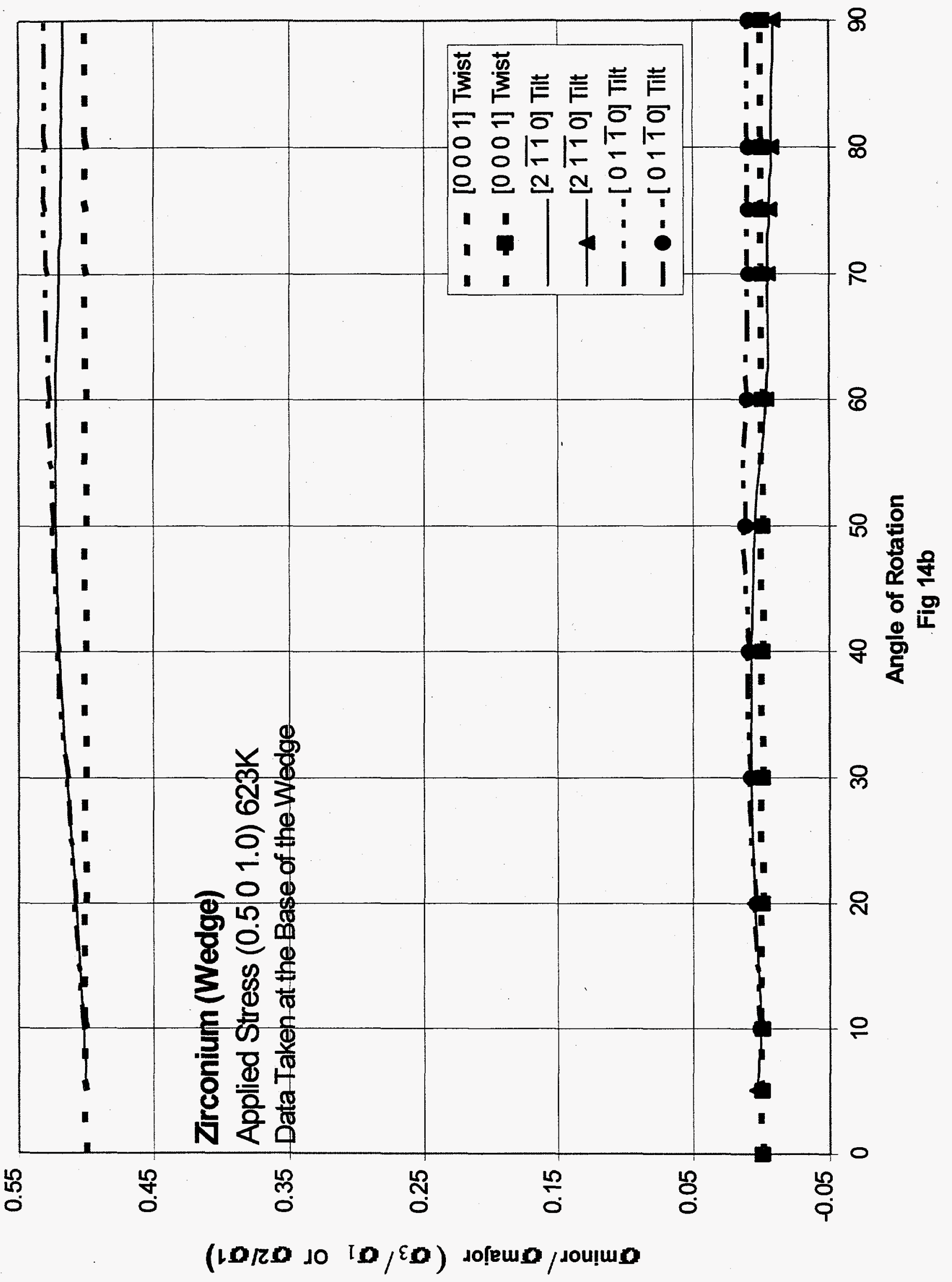

